\title{
Deviance detection in auditory subcortical structures: what can we learn from neurochemistry and neural connectivity?
}

\author{
Daniel Duque • Yaneri A. Ayala • Manuel S. Malmierca
}

Received: 11 November 2014 / Accepted: 22 January 2015

(C) Springer-Verlag Berlin Heidelberg 2015

\begin{abstract}
A remarkable ability of animals that is critical for survival is to detect and respond to to unexpected stimuli in an ever-changing world. Auditory neurons that show stimulusspecific adaptation (SSA), i.e., a decrease in their response to frequently occurring stimuli while maintaining responsiveness when different stimuli are presented, might participate in the coding of deviance occurrence. Traditionally, deviance detection is measured by the mismatch negativity (MMN) potential in studies of evoked local field potentials. We present a review of the state-of-the-art of SSA in auditory subcortical nuclei, i.e., the inferior colliculus and medial geniculate body of the thalamus, and link the differential receptor distribution and neural connectivity of those regions in which extreme SSA has been found. Furthermore, we review both SSA and MMN-like responses in auditory and non-auditory areas that exhibit multimodal sensitivities that we suggest conform to a distributed network encoding for deviance detection. The un-
\end{abstract}

Daniel Duque and Yaneri A. Ayala contributed equally to this work.

Financial support was provided by the Spanish MINECO (BFU201343608-P) and JCYL (SA343U14) to M.S.M.; D.D. held a fellowship from the Spanish MINECO (BES-2010-035649); Y.A.A. held fellowships from the Mexican CONACyT (216106) and SEP.

The funders had no role in the study design, data collection and analysis, decision to publish, or preparation of the manuscript.

D. Duque $\cdot$ Y. A. Ayala $\cdot$ M. S. Malmierca $(\bowtie)$

Auditory Neuroscience Laboratory, Institute of Neuroscience of

Castilla y León (INCyL), University of Salamanca, C/ Pintor

Fernando Gallego, 1, Salamanca 37007, Spain

e-mail:msm@usal.es

\section{S. Malmierca}

Department of Cell Biology and Pathology, Faculty of Medicine, University of Salamanca, Campus Miguel de Unamuno,

37007 Salamanca, Spain derstanding of the neurochemistry and response similarities across these different regions will contribute to a better understanding of the neural mechanism underlying deviance detection.

Keywords Auditory · Stimulus-specific adaptation . Mismatch negativity $\cdot$ Non-lemniscal $\cdot$ Inhibition $\cdot$ Deviance detection

\section{Introduction}

In everyday life, animals are immersed in a continuous flow of sounds arriving from multiple sources, and the auditory system has the challenge of selecting those acoustic elements relevant for the creation of perceptual constructs (Fishman and Steinschneider 2010). One way of organizing the acoustic scene is as follows: (1) retaining it in a form of sound objects (Winkler et al. 2009), (2) storing the regularity of the objects in a sensory memory trace, (3) generating predictions about forthcoming events, and (4) comparing the subsequent incoming sounds with these predictions (Friston 2005; Bendixen et al. 2012). This is the current theoretical processing that occurs in deviance detection (Näätänen et al. 1978, 2001) in which biological systems identify new or deviant contextual events in an otherwise monotonous auditory scene.

The occurrence of auditory deviance detection has been classically associated with the human mismatch negativity (MMN) potential of the event-related potentials (Näätänen et al. 1978). MMN is classically measured by using an oddball paradigm in which a low probability of appearance (deviant) sound is randomly embedded within sequences of common (standard) sounds. MMN is defined as the difference between the event-related potentials evoked by the deviant (larger) and the standard (smaller) sounds. Human MMN peaks between the $\mathrm{N} 1(100 \mathrm{~ms})$ and the P2 $(180 \mathrm{~ms})$ waves and can be 
interpreted as an enhancement of the N1 wave or as an independent phenomenon. This differentiation is not trivial, because the N1 wave is attributed to basic auditory processing occurring in the auditory cortex (AC; Hari et al. 1984; Maess et al. 2007), and one of the current interpretations of MMN is that adaptation is related to MMN generation (Fishman and Steinschneider 2012; Fishman 2013). Two conceptually different hypotheses have been proposed to explain the neuronal mechanisms that generate MMN. The first hypothesis is based on the "predictive coding" theory (Friston 2005) that postulates that the brain performs Bayes-optimal sensory learning under uncertainty (Friston 2009, 2012; Moran et al. 2013), whereby the brain creates a prediction concerning the identity of the next sound within an ongoing acoustic sequence based on a memory trace generated by previous stimulation. The violation of the memory-based regularity by a deviant sound would allow the generation of error signals and, therefore, MMN. On the other hand, some other authors (Jaaskelainen et al. 2004; May and Tiitinen 2010) defend a second explanation, namely the so-called "neural adaptation" hypothesis, whereby MMN reflects the release from adaptation elicited by the standard stimulus by the occurrence of a deviant sound. As neurons activated by deviant sounds are stimulated much less than neurons activated by standard sounds, such neurons are consequently less adapted and would elicit a stronger response. Thus, deviant sounds are going to elicit larger responses because adaptation for the standard sound would reduce the N1 wave. To establish the occurrence of "deviance detection", i.e., the degree of enhancement in neuronal activity evoked by the occurrence of a deviant sound that is adaptation-independent, Schröger and colleagues (Schröger and Wolff 1996; Jacobsen and Schröger 2003) have designed a paradigm to control for the probability of occurrence and therefore for the adaptation elicited by the standard tone. Control paradigms have been implemented in subsequent human (Opitz et al. 2005; Maess et al. 2007; Cacciaglia et al. 2015) and animal (rat: Taaseh et al. 2011; Harms et al. 2014) studies. This approach has allowed researchers to separate the signals contributing to MMN attributable to neuronal refractoriness from those evoked by deviance occurrence.

MMN-like phenomena are well known to occur in several different animals, including cats (Csepe et al. 1987a, 1987b; Pincze et al. 2001, 2002), monkeys (Javitt et al. 1992, 1994; Fishman and Steinschneider 2012), guinea pigs (Kraus et al. 1994a, 1994b; Christianson et al. 2014), rabbits (Ruusuvirta et al. 1995a, 2010), rats (Ruusuvirta et al. 1998, 2013; Astikainen et al. 2006, 2011; Nakamura et al. 2011; Jung et al. 2013; Shiramatsu et al. 2013; Harms et al. 2014), and mice (Siegel et al. 2003; Umbricht et al. 2005). Recently, it has been reported that the rat brain is capable of generating human-MMN-like responses, and moreover, that part of the MMN signal is independent of adaptation driven by memorylike processing (Astikainen et al. 2006; Harms et al. 2014). In agreement with this study, true-deviance detection is also reflected at the single neuron level in the rat AC (Taaseh et al. 2011). Although deviance encoding has been largely thought to involve pure cortical processing, an elegant and recent study by Cacciaglia and colleagues (2015) has demonstrated that the human inferior colliculus (IC) and medial geniculate body (MGB) of the thalamus exhibit genuine deviance detection. This study confirms previous data indicating deviance detection at very short latency responses $(\sim 30-40 \mathrm{~ms})$ in auditory-evoked potentials (Slabu et al. 2010, 2012).

Here, in an attempt to gain a better understanding of deviance detection, we review the anatomy and immunocytochemistry of the IC and MGB, since they might reveal the general organizational principles of the subcortical network for deviance detection. Likewise, we present data concerning auditory mismatch responses in non-auditory subcortical structures that might be part of the same network.

\section{Stimulus-specific adaptation}

Using the same oddball paradigm as in human MMN studies, Ulanovsky et al. (2003) have found that AC neurons of the cat reduce their response to frequently occurring stimuli (standard) but resume their firing when different rare stimuli are presented (deviant). This neuronal response has been referred to as stimulus-specific adaptation (SSA; Movshon and Lennie 1979). Later studies have demonstrated that SSA also occurs in the IC (rat: Perez-Gonzalez et al. 2005; Malmierca et al. 2009; Duque et al. 2012; Ayala et al. 2013) and the MGB (mouse: Anderson et al. 2009; rat: Antunes et al. 2010). By contrast, neurons in the cochlear nucleus lack SSA (rat: Ayala et al. 2013), suggesting that the IC is the first auditory relay station in which SSA occurs.

Throughout the auditory collicular, thalamic, and cortical areas, SSA has several common characteristics that are similar to the human MMN. SSA is a rapid phenomenon, with a time scale of a few seconds (Ulanovsky et al. 2004; Malmierca et al. 2009; Ayala and Malmierca 2013), and is highly sensitive to stimulus statistics: the smaller the probability of occurrence for the deviant, the larger the SSA (Ulanovsky et al. 2003; Malmierca et al. 2009; Antunes et al. 2010; Zhao et al. 2011; Ayala et al. 2013). These same studies have also revealed that increasing the frequency contrast (the physical separation between the two tones) or the presentation rate (the speed to which the tones are repeated) evokes stronger SSA responses, although SSA can be observed at interstimulus intervals as long as $2000 \mathrm{~ms}$ (Ulanovsky et al. 2003; Antunes et al. 2010; Ayala and Malmierca 2013, Fig. 1). As SSA in the AC was first observed in the core region of the AC (Ulanovsky et al. 2003), some authors proposed SSA emerged in the AC as a high order feature that can be "inherited" by the 
Fig. 1 Grand-average responses of neurons in the inferior colliculus (IC), the medial geniculate body $(M G B)$, and the auditory cortex $(A C)$. Averaged peristimulus time histograms (PSTH) for the entire population of neurons recorded at various frequency contrasts $(\Delta f)$ for a standard/deviant ratio of $90 / 10 \%$. The mean firing rate elicited by both stimuli (blue lines standard, red lines deviant) increased at the different $\Delta f(\Delta f=0.04,0.1$, and 0.37 ; from left to right, respectively). Black horizontal lines under the PSTHs indicate the duration of the stimulus: $230 \mathrm{~ms}$ for the AC study and $75 \mathrm{~ms}$ for the IC and MGB studies (modified from Ulanovsky et al. 2003; Malmierca et al. 2009; Antunes et al. 2010)

$$
\Delta f=0.04
$$
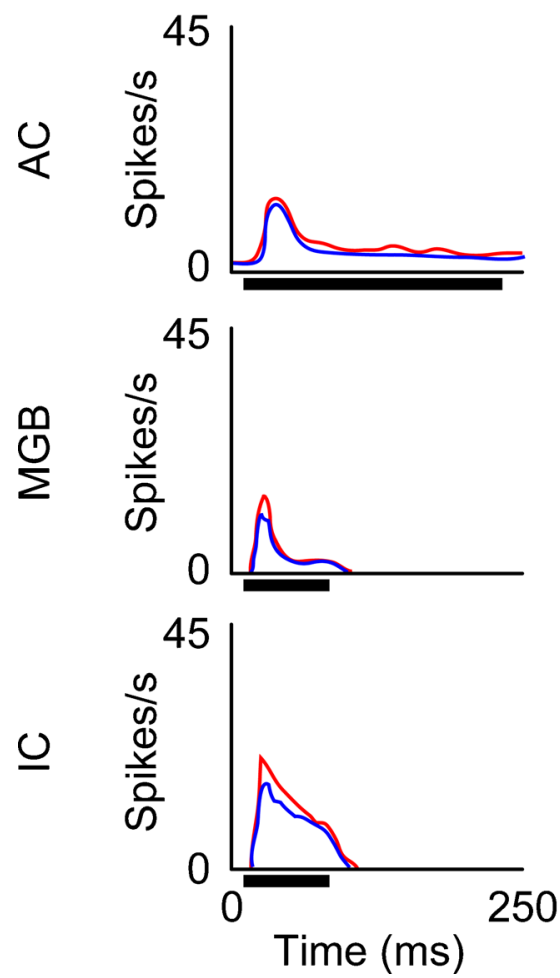

$\Delta f=0.1$
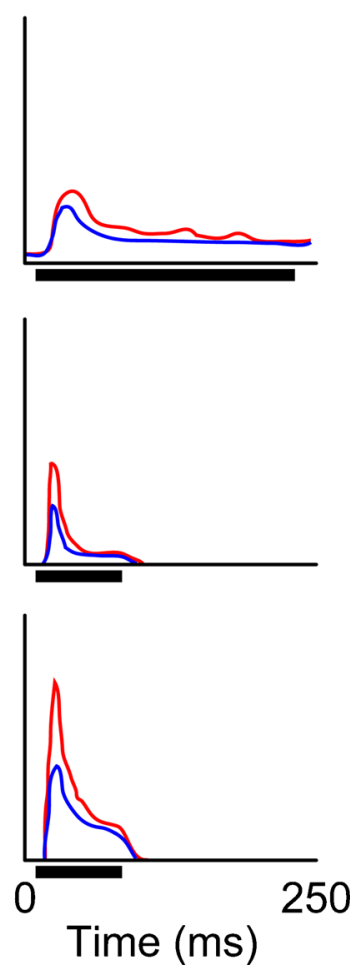

$\Delta f=0.37$
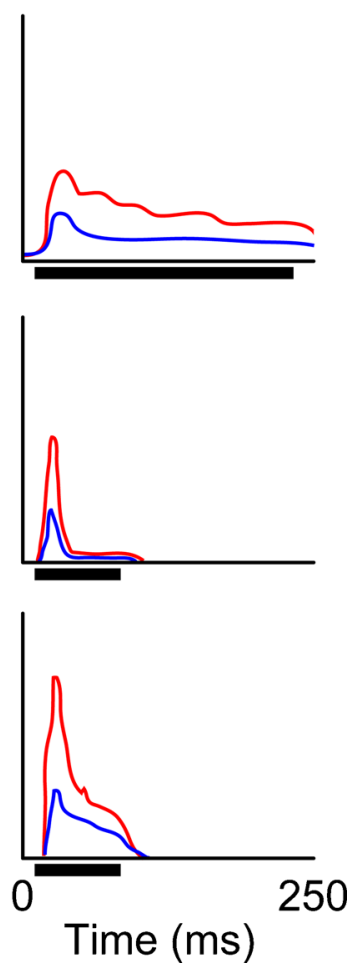

IC and the MGB via the corticofugal pathway (Nelken and Ulanovsky 2007; Bäuerle et al. 2011). However, recent studies with the powerful technique of cortical cooling (Antunes and Malmierca 2011; Anderson and Malmierca 2013) have demonstrated that the corticofugal projections arising from the core AC regions modulate, but do not generate, subcortical SSA. Currently, SSA is thought to be created de novo at each auditory station or to be transmitted in a cascade process from low to higher order nuclei. In this review, we will describe possible mechanisms involved in SSA, with special emphasis on the anatomical substrate that might underlie the connectivity of SSA neurons and on the receptor distributions in the subcortical nuclei of the IC and the MGB.

Throughout the following, SSA will be used to describe a specific reduction of the responses at a neuronal level, whereas MMN (or MMN-like) will be used for differential responses observed at local field potentials. Conceptually, this is different from deviance detection, which refers to an enhancement in the neuronal response evoked by the occurrence of a rare sound and which is independent of adaptation.

\section{SSA is not homogenously distributed in IC and MGB; connectivity of lemniscal and non-lemniscal subdivisions}

Auditory processing between the midbrain and the cortex is carried by two parallel streams: the lemniscal (or primary) and non-lemiscal (or secondary) pathways (Fig. 2; Andersen et al.
1980; Lee and Sherman 2010, 2011). The non-lemniscal system comprises the lateral (LCIC), the rostral (RCIC), and the dorsal cortex (DCIC; Loftus et al. 2008, 2010) of the IC and the dorsal (MGBd) and medial subdivisions (MGBm) of the MGB in the thalamus. On the other hand, the lemniscal system comprises the central nucleus of the IC (CNIC) and the ventral division of the MGB (MGBv). Across these subcortical nuclei, SSA responses are not homogenously distributed. Neurons in the cortices of the IC (rat: Malmierca et al. 2009; Duque et al. 2012; Ayala et al. 2013) and in the MGBd and MGBm (mouse: Anderson et al. 2009; rat: Antunes et al. 2010) exhibit the strongest SSA responses. In agreement with SSA data, a pioneering study by Kraus et al. (1994b) has shown that auditory stimuli containing different frequencies or intensities consistently produce a mismatched field potential in the non-lemniscal divisions of the thalamus but not in the MGBv of the guinea pig (Fig. 3). Although such correlation has not been confirmed in the rat AC (Fig. 3, Nakamura et al. 2011; Jung et al. 2013; Shiramatsu et al. 2013), all these data suggest that subcortical acoustic deviance detection is primarily computed by neurons of the non-lemniscal pathway.

Lemniscal and non-lemniscal neurons differ in (1) their response properties (cat: Aitkin et al. 1975; Calford 1983; Calford and Aitkin 1983; Aitkin and Prain 1974; mouse: Anderson and Linden 2011; rat: Lumani and Zhang 2010), (2) their fine morphology, i.e., terminal size and arborization pattern (Oliver 2005; rat: Malmierca et al. 1995; 2011; Stebbings et al. 2014), and in (3) their set of afferent and 


\section{Inferior colliculus}

Medial geniculate body

Auditory cortex

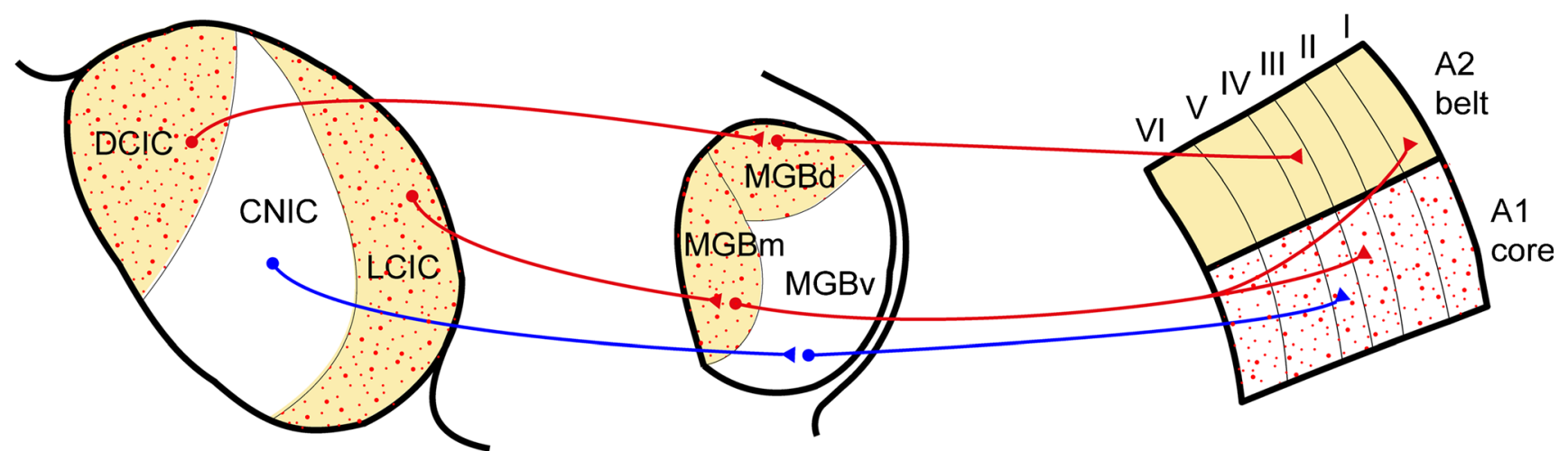

\section{Non-lemniscal regions Lemniscal regions}

Fig. 2 Topographic segregation of the lemniscal and non-lemniscal projections between the inferior colliculus (IC), medial geniculate body (MGB) and auditory cortex (AC). The strongest SSA responses are distributed in the non-lemniscal subdivisions (shaded areas) of the IC (DCIC dorsal cortex, LCIC lateral cortex, RCIC rostral cortex) and MGB ( $M G B d$ dorsal subdivision, $M G B m$ medial subdivision). On the contrary, poor SSA responses are found in the lemniscal areas of the IC

\section{Non-lemniscal pathway Lemniscal pathway}

(CNIC central nucleus) and MGB ( $M G B v$ ventral subdivision). At the cortical level, the primary auditory cortex $(A 1)$ exhibits SSA responses that remain to be addressed in areas beyond A1. The major bottom-up projections between non-lemniscal (red) and lemniscal (blue) collicular, thalamic, and cortical areas are illustrated by lines (modified from Escera and Malmierca 2014)

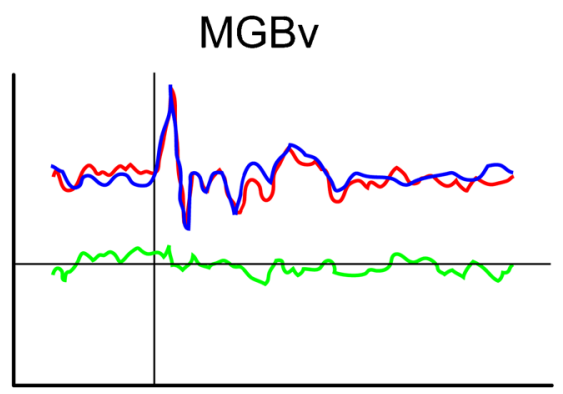

Core auditory cortex
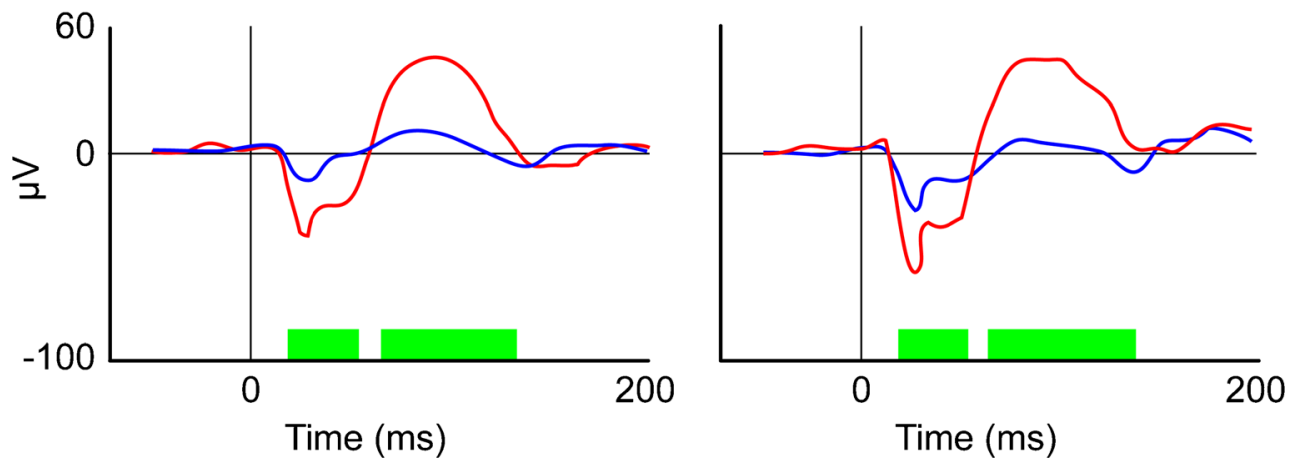

Auditory evoked potentials to deviant (red lines) and standard stimuli (blue lines) elicited in a non-lemniscal region of the AC (left posterior auditory field) and in the core region of the AC of the rat (right). Significant differences between the responses to standard and deviant stimuli are indicated by the green boxes. Unlike the MGB, MMN-like waves in the AC have not been shown to be spatially distributed (modified from Kraus et al. 1994a; Jung et al. 2013) 
efferent projections (rat: Coleman and Clerici 1987; Malmierca and Hackett 2010; for reviews, see Hu 2003; Lee and Sherman 2011). Lemniscal neurons are tonotopically organized exhibiting fast and high-fidelity responses (cat: Miller et al. 2001; rat: Malmierca et al. 2008), whereas non-lemniscal neurons are not tonotopically organized and show longer latencies and habituating responses to unvarying stimuli (cat: Calford 1983; Calford and Aitkin 1983; rat: Bordi and LeDoux 1994a, 1994b; Malmierca et al. 2009; guinea pig: $\mathrm{He}$ and $\mathrm{Hu}$ 2002). Furthermore, non-lemniscal neurons show broader frequency response areas, i.e., the combination of frequencies and intensities capable of evoking a response (Lennartz and Weinberger 1992; Perez-Gonzalez et al. 2005; Malmierca et al. 2009; Duque et al. 2012; Ayala et al. 2013) and respond preferentially to complex acoustic stimuli (cat: Aitkin et al. 1975). Moreover, the basal discharge and response strength are lower in the non-lemniscal than lemniscal neurons of the IC (rat: Duque et al. 2012) and MGB (cat: Aitkin and Prain 1974; Calford and Aitkin 1983). Interestingly, both the bandwidth of the frequency responses areas (rat: Duque et al. 2012; Ayala et al. 2013) and the onset firing pattern (rat: Duque et al. 2012) correlates with the strength of the SSA responses of IC neurons. Regarding their connectivity, the CNIC primarily sends excitatory and inhibitory projections to the MGBv (for reviews, see Oliver and Huerta 1992; Wenstrup 2005) with a high degree of topographic convergence (Lee and Sherman 2011), whereas the cortices of the IC innervate primarily the MGBd and MGBm (mouse: Romand and Ehret 1990; for reviews, see Hu 2003; Wenstrup 2005). At the level of the MGB, two major afferent streams arise en route to the auditory cortices (cat: Huang and Winer 2000; for a review, see Hu 2003). Generally speaking, secondary auditory cortices are targeted principally by nontonotopic subcortical areas that mainly terminate in layer 1, whereas primary auditory cortices principally receive inputs from tonotopic lemniscal areas that target mainly the middle layers (cat: Kudo and Niimi 1980; Huang and Winer 2000; Lee and Winer 2011; for a review, see Winer 1992).

Traditionally, the early sensory processing neuronal stages are assumed to be unimodal and to operate independently of each other. However, a growing body of evidence has changed this classical view of the sensory hierarchical processing by demonstrating the convergence of multimodal inputs in subcortical nuclei (Stein and Meredith 1993; Stein and Stanford 2008) and early primary sensory cortices (Ghazanfar et al. 2005; Kayser and Logothetis 2007; Lakatos et al. 2007; King and Walker 2012; for a review, see Kayser et al. 2012). In agreement with the above-mentioned, another feature of the non-lemniscal tectal and thalamic areas includes their dense innervation by non-auditory afferents. For instance, the shell area of the IC receives visual (rat and monkey: Itaya and Van Hoesen 1982; rat: Yamauchi and Yamadori 1982; cat: Mascetti and Strozzi 1988) and somatosensory (cat: Aitkin et al. 1978, 1981; Coleman and Clerici 1987; for a review, see Wu et al. 2014) inputs and projections from the substantia nigra pars compacta lateralis (cat: Coleman and Clerici 1987), globus pallidus (rat: Yasui et al. 1991; cat: Shinonaga et al. 1992), and the ventral tegmental area (rat: Herbert et al. 1997). Likewise, the MGBd and MGBm are innervated by afferents from the tegmental nuclei, spinothalamic tract, and superior colliculus (cat: Graybiel 1972; rat: Ledoux et al. 1987; Iwata et al. 1992). The efferent connections of the non-lemniscal areas of the IC (cat: Aitkin et al. 1978; ferret: King et al. 1998) and MGB (cat: Shinonaga et al. 1994; rat: Doron and Ledoux 1999; 2000) also display divergent projections to nonauditory nuclei.

Together, these structural differences are associated with the different functions exerted by the lemniscal and nonlemniscal systems. The lemniscal pathway is associated primarily with the relay of purely auditory information, whereas the non-lemniscal pathway is part of an integrative system primarily involved in multisensory integration, temporal pattern recognition (cat: Kelly 1973; Layton et al. 1979), change detection (guinea pig: Kraus et al. 1994a; rat: Malmierca et al. 2009), and certain forms of learning (guinea pig: Edeline and Weinberger 1991; rat: Komura et al. 2001). Furthermore, the multimodal afferent and efferent projections characterizing the non-lemniscal pathway are potentially important for sound localization, attending to salient stimuli, and mediating the audio-visual integration of speech stimuli (human: Champoux et al. 2006; for reviews, see Gruters and Groh 2012; Wu et al. 2014).

\section{Major excitatory and inhibitory neurotransmitter receptors}

The distribution and expression of receptor subtypes for neurotransmitters and neuromodulators show subtle differences in the IC and MGB subdivisions (summarized in Table 1).

Excitatory neurotransmission is mediated by glutamate in both the IC (cat: Adams and Wenthold 1979) and the MGB (rat: Hu et al. 1994). Both ionotropic AMPA ( $\alpha$-amino-3-hydroxy-5-methylisoxazole-4-propionic acid) and NMDA (Nmethyl-D-aspartate) receptors intervene in the synaptic transmission of the IC (rat: Ma et al. 2002; for a review, see Kelly and Zhang 2002) and the MGB (rat: Hu et al. 1994), but recordings from the non-lemniscal regions of the IC do not provide evidence for pharmacological differences from the CNIC (rat: Li et al. 1998, 1999). Immunostaining for AMPA receptors is homogeneous throughout the IC (rat: Petralia and Wenthold 1992; Gaza and Ribak 1997), although the presence of the GluR2-3 AMPA subunit is more common in the nonlemniscal regions of the IC (rat: Caicedo and Eybalin 1999). Additionally, NMDA receptors are more common in the LCIC and the DCIC (rat: Petralia et al. 1994). In accordance with the 
Table 1 Main receptor distribution in the human inferior colliculus (IC) and medial geniculate body $(M G B)$ shown with density ( - absent, + to +++ increasing density levels, SSA stimulus-specific adaptation, $C N I C$ central nucleus of IC, LCIC lateral cortex, RCIC rostral cortex, DCIC dorsal cortex, $M G B v$ ventral division of MGB, $M G B d$ dorsal subdivision of MGB, $M G B m$ medial subdivision of MGB, $A M P A \alpha$-amino-3-hydroxy-5-methylisoxazole-4-propionic acid, $N M D A$ N-methyl-D-aspartate, GABA Gamma aminobutryic acid, $n N O S$ Neural nitric oxide synthase)

\begin{tabular}{|c|c|c|c|c|c|c|c|c|c|}
\hline \multicolumn{2}{|c|}{ Transmitter type receptor } & \multicolumn{4}{|l|}{ IC } & \multicolumn{3}{|l|}{ MGB } & \multirow[t]{3}{*}{ SSA implication } \\
\hline & & \multirow{2}{*}{$\begin{array}{l}\text { Lemniscal } \\
\text { CNIC }\end{array}$} & \multicolumn{3}{|c|}{ Non-lemniscal } & \multirow{2}{*}{$\begin{array}{l}\text { Lemniscal } \\
\text { MGBv }\end{array}$} & \multicolumn{2}{|c|}{ Non-lemniscal } & \\
\hline & & & DCIC & LCIC & $\mathrm{RCIC}$ & & MGBd & MGBm & \\
\hline \multirow[t]{3}{*}{ Glutamate } & AMPA & \multicolumn{4}{|c|}{ Homogeneous } & \multicolumn{3}{|c|}{ Homogeneous } & Unlikely \\
\hline & NMDA & + & +++ & & & + & +++ & & Likely \\
\hline & mGluR & - & +++ & & & - & +++ & & Likely \\
\hline \multirow[t]{2}{*}{ GABA } & A & Dorsal & Clusters & & & \multicolumn{3}{|c|}{ Homogeneous } & Gain control \\
\hline & $\mathrm{B}$ & +++ & + & +++ & + & +++ & +++ & - & Low \\
\hline Glycine & & Ventral & + & & & - & - & - & Unlikely, IC only \\
\hline \multirow[t]{2}{*}{ Acetylcholine } & Muscarinic & - & + & + & - & \multicolumn{3}{|c|}{ Homogeneous } & Attention? \\
\hline & Nicotinic & - & +++ & +++ & - & \multicolumn{3}{|c|}{ Homogeneous } & Attention? \\
\hline \multicolumn{2}{|l|}{ Serotonin } & + & +++ & +++ & +++ & + & +++ & Unknown & Attention? \\
\hline \multicolumn{2}{|l|}{ Norepinephrine } & + & +++ & +++ & +++ & Unknown & & & Learning? \\
\hline \multicolumn{2}{|l|}{ Dopamine } & + & +++ & +++ & +++ & Very low & & & Learning? IC only \\
\hline \multicolumn{2}{|c|}{ Endocannabinoids } & Unknown & Unknown & Present & & Unknown & & & Speculative \\
\hline \multicolumn{2}{|l|}{ nNOS } & + & +++ & +++ & +++ & Unknown & & & Speculative \\
\hline \multicolumn{2}{|l|}{ Dynorphin } & + & + & +++ & +++ & Unknown & & & Unknown \\
\hline \multicolumn{2}{|l|}{ Enkephalin } & \multicolumn{4}{|c|}{ Homogeneous } & Unknown & & & Unlikely \\
\hline Substance P & & + & +++ & +++ & +++ & Unknown & & & Speculative \\
\hline
\end{tabular}

IC data, the presence of AMPA receptors in the MGB has been proved to be homogeneous and moderate in quantity (rat: Sato et al. 1993; Caicedo et al. 1998; for a review, see Parks 2000), whereas the presence of NMDA receptors seems more prominent in the non-lemniscal regions of the MGB (rat: Monaghan and Cotman 1985; Hu et al. 1994). Immunohistochemical studies have also demonstrated the presence of the metabotropic glutamate receptor $\mathrm{mGluR}_{5}$ in the cortical regions of the IC (rat: Abe et al. 1992; Shigemoto et al. 1993). Group I mGluRs, including $\mathrm{mGluR}_{1}$ and $\mathrm{mGluR}_{5}$, are located mostly on postsynaptic parts of cells and act by increasing NMDA activity. Projections from the DCIC and LCIC to the non-lemniscal regions of the MGB recruit mGluR (rat: Bartlett and Smith 2002; mice: Lee and Sherman 2010), as opposed to the mainly ionotropic component of the postsynaptic receptors of the MGBv (for a review, see Lee and Sherman 2011). As NMDA receptors are classically linked to synaptic plasticity, learning, and memory (Morris 2013), the testing of the role, if any, that the NMDA receptors play on shaping SSA would be of great interest in future studies.

Inhibitory neurotransmission in the IC is mediated by both gamma-aminobutryric acid (GABA) and glycine (for a review, see Cant and Benson 2003). GABA $A$ receptors are located in more dorsal regions of the IC (gerbil: Sanes et al. 1987; bat: Fubara et al. 1996; Lu and Jen 2001), whereas glycine puncta are more prominent in the ventral region of the IC (cat: Adams and Wenthold 1979; Saint Marie et al. 1989; rat: Merchan et al. 2005). Nevertheless, this is not the only pattern of distribution that emerges with inhibition in the IC, as GABAergic neurons are also organized in cluster modules in the DCIC and the LCIC (rat: Chernock et al. 2004), with an unknown function. Additionally, metabotropic $\mathrm{GABA}_{\mathrm{B}}$ receptors are present to a greater extent in the CNIC and the LCIC (rat: Bowery et al. 1983; bat: Fubara et al. 1996; rat: Jamal et al. 2011, 2012). In the thalamus, inhibition in the MGB is primarily mediated by GABA acting at both $\mathrm{GABA}_{\mathrm{A}}$ and $\mathrm{GABA}_{\mathrm{B}}$ receptors (rat: Bartlett and Smith 1999; Richardson et al. 2011), because MGB lacks glycinergic receptors (rat: Aoki et al. 1988; Friauf et al. 1997). GABAergic interneurons are virtually absent in the rat MGB (only 1 \%: Winer and Larue 1996; Bartlett and Smith 1999), but in this case, the nucleus receives significant GABAergic projections from the IC (bat, rat, cat, and monkey: Winer et al. 1996; rat: Peruzzi et al. 1997; mice and rat: Ito et al. 2011) and the thalamic reticular nucleus (cat: Rouiller et al. 1985).

Recent studies have addressed the effect of neuronal inhibition on SSA by local manipulation of GABA neurotransmission (Fig. 4). The blockade of the $\mathrm{GABA}_{\mathrm{A}}$ receptor by using the specific antagonist gabazine elicits an overall increase in the evoked and spontaneous activity in IC (rat: Perez-Gonzalez et al. 2012) and MGB (rat: Duque et al. 
2014) neurons. This increase in neuronal discharge is independent of the SSA sensitivity and their discharge pattern. Together, these studies demonstrate that the blockade of $\mathrm{GABA}_{\mathrm{A}}$ receptors of IC and MGB neurons with high SSA sensitivity (typically located in non-lemniscal regions) does not abolish SSA (rat: Perez-Gonzalez et al. 2012; Duque et al. 2014), suggesting that the GABAergic system exerts a gain control function on the neuronal responses. Furthermore, the experiments performed in the MGB by Duque et al. (2014) suggest that the ability of GABA to modulate SSA in the MGB is likely to be mediated by the $\mathrm{GABA}_{\mathrm{A}}$ rather than by the $\mathrm{GABA}_{\mathrm{B}}$ receptors. The effects of gaboxadol, a $\mathrm{GABA}_{\mathrm{A}^{-}}$ selective agonist that does not bind to $\mathrm{GABA}_{\mathrm{B}}$ receptors (rat: Bowery et al. 1983), are no different from the effects elicited by GABA on SSA in MGB. Moreover, as the highest levels of SSA are found in the MGBm (rat: Antunes et al. 2010), an area that lacks $\mathrm{GABA}_{\mathrm{B}}$ receptors (rat: Smith et al. 2007), these metabotropic receptors do not seem to be involved in SSA generation. However, any possible synergic effect as a result of the co-application of antagonist or agonists of other subunit or subtype receptors cannot be excluded.

Indeed, as metabotropic receptors (mainly $\mathrm{GABA}_{\mathrm{B}}$ ) are linked to calcium $\left(\mathrm{Ca}^{2+}\right)$ signaling, $\mathrm{Ca}^{2+}$-binding proteins (namely parvalbumin, calbindin, and calretinin) largely define the lemniscal and non-lemniscal pathways (monkey: Jones 2003; human: Tardif et al. 2003; bats and birds: Covey and Carr 2005; rat: Ouda and Syka 2012). In the IC, parvalbumin is distributed throughout the subdivisions but with a larger presence in the CNIC (bat: Vater and Braun 1994; rat: Lohmann and Friauf 1996; Ouda and Syka 2012). On the other hand, calretinin- and calbindin-positive neurons are usually located in the non-lemniscal regions of the IC (bat: Zettel et al. 1991; rat: Ouda and Syka 2012). In the MGB, parvalbumin is also associated with the lemniscal regions, whereas calbindin is associated with the non-lemniscal regions (rabbit: de Venecia et al. 1995; monkey: Molinari et al. 1995; mice: Cruikshank et al. 2001). The parvalbumin (lemniscal) and calbindin/ calretinin (non-lemniscal) distributions are also maintained in the AC (Banks and Smith 2011). The presence of these $\mathrm{Ca}^{2+}$ related proteins might play a critical role in second messenger systems (see: Neuronal mechanisms that might underlie SSA: synaptic depression and retrograde signaling).

Finally, although the presence of glycine in the nonlemniscal regions of the IC is small (Adams and Wenthold 1979; Merchan et al. 2005), the effect of glycinergic receptors in IC neurons on SSA remains unknown. This is an important point, because IC neurons show higher SSA sensitivity at high frequencies (Duque et al. 2012), and glycine is more abundant in the ventral region of the IC (Malmierca and Hackett 2010), a region whose neurons are high-frequency tuned (Malmierca et al. 2008). Thus, in order to have a global picture of the mechanisms that might operate at subcortical SSA, several open questions remain to be answered. Among others, these include: what is the effect on SSA mediated by the combined activation of the $\mathrm{GABA}_{\mathrm{A}^{-}}$and $\mathrm{GABA}_{\mathrm{B}}$-receptors and glycinergic receptors, and what is the role, if any, of the NMDA-mediated excitation. Lastly, as will be explained in the following sections, the interactions of any of these systems with specific retrograde messengers could also be crucial to an understanding of the mechanisms that generate SSA.

\section{Neuromodulators in IC and MGB}

Recent studies have envisaged a pivotal role of neuromodulators on orienting attention and enhancing the memory for novel stimuli (for reviews, see Ranganath and Rainer 2003; Edeline 2012). Indeed, the four neuromodulatory systems, namely cholinergic (Metherate et al. 2012), serotoninergic (Hurley and Sullivan 2012), dopaminergic (Gittelman et al. 2013), and noradrenergic (Manunta and Edeline 2004), have been implicated in short-term plastic auditory phenomena suggesting that they might also mediate SSA.

Acetylcholine has been implicated in predictive coding and learning under uncertainty in humans (Moran et al. 2013). Moreover, acetylcholine is known to exert frequencyspecific plasticity in both cortical (cat: Metherate and Weinberger 1989) and subcortical (bat: Ji et al. 2001) neurons. Cholinergic terminals are abundant in the DCIC and the LCIC (guinea pig: Jain and Shore 2006; for a review, see Shore 2008), and the receptors in these regions are mainly nicotinic. In the MGB, almost all the neurons present either muscarinic and/or nicotinic receptors and are excited by acetylcholine (cat: Tebecis 1970, 1972). Acetylcholine depolarizes most of the neurons in the lemniscal MGBv through the muscarinic receptors, whereas a large amount of the neurons in the MGBd remain unaffected (rat: Varela and Sherman 2007; for a review, see Varela 2014).

Serotoninergic projections to all the regions of the IC arise from the raphe nuclei (bat: Hurley and Pollak 2005), although fibers are denser in non-lemniscal regions such as the DCIC and the LCIC (for reviews, see Hurley et al. 2002; Hurley and Sullivan 2012). Raphe nuclei also present projections to the MGB (monkey: Lavoie and Parent 1991; rat: Vertes et al. 2010), modulating the responses of many of the neurons in the lemniscal MGBv and most of the neurons in the nonlemniscal MGBd (guinea pig: Pape and McCormick 1989; cat: McCormick and Pape 1990; ferret: Monckton and McCormick 2002; rat: Varela and Sherman 2009; Varela 2014).

Attention during task engagement is known to modulate neuronal responses (ferrets: Fritz et al. 2003, 2007), and thus, attention mediated by either acetylcholine or serotonin might produce this modulation, hence affecting the levels of SSA. Indeed, recent work concerning SSA in the IC of the awake mouse (Duque and Malmierca 2014) has demonstrated that 
the lower the spontaneous firing rates, the higher the SSA sensitivity. As spontaneous activity can be modulated during attention and can enhance signal detection (gerbils: Buran et al. 2014), both neuromodulators might be involved in SSA sensitivity. In view of the involvement acetylcholine (Jones 2005) and serotonin (Kelly and Caspary 2005) in arousal and attention, the effect of such neurotransmitters on SSA might be more important than previously estimated, and we need further studies in this field.

The response of the neurons of the IC and the MGB are also affected by catecholamines, mainly through noradrenergic- (rat: Swanson and Hartman 1975; Foote et al. 1983; Klepper and Herbert 1991) and dopaminergic (rat, cat and bat: Olazabal and Moore 1989; cat: Paloff and Usunoff 2000) fibers. The locus coeruleus is the main source of noradrenaline for both the IC and the MGB (Aston-Jones 2004). The dopaminergic innervation for the IC arises from neurons in the substantia nigra (Moore and Bloom 1979; Olazabal and Moore 1989), whereas the dopamine sources for the MGB are highly diverse (macaque: Sanchez-Gonzalez et al. 2005). Recent findings suggest that the noradrenergic direct projection from the locus coeruleus to the IC is mainly ipsilateral and just reaches the non-lemniscal regions of the IC (rat: Klepper and Herbert 1991; Hormigo et al. 2012). The dopaminergic neurons identified in the IC also have a distinct distribution, the largest number of dopaminergic neurons being located in the LCIC and the DCIC (rat: Tong et al. 2005).

In summary, considering that (1) noradrenaline and dopamine act as learning signals, and both neuromodulators are released at times of novelty and uncertainty (Harley 2004), and that (2) acetylcholine and serotonin mediate attention, their involvement in SSA sensitivity might be critical. Since SSA is a pre-attentive feature observed under anesthesia (rat: Malmierca et al. 2009), in awake (mouse: Duque and Malmierca 2014), and sleep-like states (rat: Nir et al. 2013), SSA is probably affected by the variations in the levels of neuromodulators occurring during these states. Thus, future studies of the various modulatory substances will undoubtedly shed light on the way that the brain learns to discriminate potentially relevant sounds (Edeline 2012).

\section{Neuronal mechanisms that might underlie SSA: synaptic depression and retrograde signaling}

Since GABAergic inhibition plays a key role in modulating SSA rather than in its generation (Perez-Gonzalez et al. 2012; Duque et al. 2014), a synaptic depression model (Grill-Spector et al. 2006; Briley and Krumbholz 2013) might be a more likely explanation for SSA. In this model, the continuous activation of the same set of neurons will eventually produce a specific decrease of the neurotransmitter release at the presynaptic level, and consequently, the postsynaptic neuron will not generate a response.
The frequency-specific adaptation channel theory supports this model (Eytan et al. 2003; Mill et al. 2011a, 2011b; Taaseh et al. 2011; Nelken 2014) in which all the frequencies that are within the same frequency channel will not evoke SSA, because they are encoded by the same neurons. Although recent data from the rat AC (Hershenhoren et al. 2014) suggest other, as yet unknown, more complex mechanisms to explain SSA at the cortical level, in the IC, SSA is not constant within the neuronal receptive field of the neuron, and SSA sensitivity is stronger on the high-frequency edge of the receptive field (Duque et al. 2012). This phenomenon presents interesting correlates in the auditory nerve fibers (Westerman and Smith 1985) and the IC (Dean et al. 2008) in which adaptation is also more prominent at high frequencies. Together, these studies suggest that synaptic depression (Chung et al. 2002; Rothman et al. 2009) might explain subcortical SSA, as it is an input-specific mechanism, and neural responses depend upon the previous history of afferent firing (Abbott et al. 1997; Rothman et al. 2009).

Moreover, as various retrograde signaling pathways can act at the synaptic level (Regehr et al. 2009), synaptic depression does not necessarily have to be a passive phenomenon (i.e., fatigue). Retrograde signaling mediates short-term synaptic plasticity (Regehr 2012), a likely explanation for synaptic depression (Abbott and Regehr 2004): lipids (endocannabinoids), gases (nitric oxide), peptides (i.e., met-enkephalin and/or dynorphin), and conventional amino acid transmitters (i.e., glutamate and/or GABA) can be released in an activation-dependent manner by postsynaptic neurons and then act on the axon terminals of presynaptic neurons (Regehr et al. 2009). The production and release of these messengers is regulated by the activation of postsynaptic glutamatergic metabotropic receptors (Regehr et al. 2009) and/or by postsynaptic $\mathrm{Ca}^{2+}$ (de Jong and Verhage 2009), two components mainly located in the non-lemniscal regions of the IC and the MGB (see above). In the mammalian brain, the endocannabinoid signaling system is the bestcharacterized retrograde signaling pathway and enables neurons specifically to regulate the strength of their inputs in a retrograde manner (Wilson and Nicoll 2002; Freund and Hajos 2003; Kano et al. 2009). Endocannabinoid type-1 (CB1) receptors are thought to be one of the most widely expressed G-proteincoupled receptors in the brain (Herkenham et al. 1990). The presynaptic localization of $\mathrm{CB} 1$ receptors and their inhibitory effect on neurotransmitter release has been shown to be a general feature of most axon terminals in the central nervous system (Kano et al. 2009), suppressing synaptic strength for tens of seconds (Wilson et al. 2001). The firing evoked by the standard stimuli in an oddball paradigm can activate group I mGluR, thus inducing endocannabinoid release (Chevaleyre et al. 2006) and contributing to short-term synaptic plasticity (Castillo et al. 2012), as in the fast adaptation occurring in the neuronal firing to the standard tone. Endocannabinoid signaling has been demonstrated to act in the auditory pathway at the level of the cochlear nucleus (Zhao et al. 2009; Zhao and Tzounopoulos 2011), 
the superior olivary complex (Trattner et al. 2013), and the external cortex of the IC of the barn owl (Penzo and Pena 2009), but its affect on auditory SSA remains unknown.

Much less is known about other retrograde neurotransmitters. For example, the highest levels of nNOS (the neuronal enzyme that synthesizes nitric oxide) are evident in the DCIC and the LCIC, with much lower levels in the CNIC (Druga and Syka 1993; Paloff and Hinova-Palova 1998; Coote and Rees 2008). Few data are available for understanding the involvement of nNOS in the MGB. As another example, immunostaining for kappa $(\kappa)$ opioid receptors (dynorphin) is significantly higher in the LCIC, but delta $(\delta)$ opioid receptors (met-enkephalins) are similarly distributed within the IC (Aguilar et al. 2004; Tongjaroenbuangam et al. 2006). Thus, the distribution of the opioid receptors cannot be correlated with specific regions of the IC. The data regarding opioid receptor distribution in the MGB are also sparse and difficult to interpret. Lastly, we should mention the existence of extensive labeling for fibers with both somatostatin and substance-P in the DCIC and the LCIC, with somatostatin showing the most extensive encircling of the CNIC (Wynne and Robertson 1997). Interestingly, no significant fibers labeling for either peptide have been observed within the CNIC (Wynne and Robertson 1997). Unfortunately, the involvement of retrograde signaling in SSA remains unknown, and much work is needed to gain an understanding of the functions of these systems in sound discrimination.

\section{Detection of acoustic deviance in non-auditory nuclei}

Beyond the auditory pathway, stronger neuronal responses to deviant sounds have also been found in some non-auditory

Fig. 4 Effect of neuronal inhibition on the SSA responses in IC and MGB neurons. a Dot raster plots obtained after an oddball paradigm for a pair of frequencies in an IC neuron. The dot rasters refer to the control (left), gabazine (GBZN, middle), and recovery (right) conditions. Frequencies are shown as insets over the control condition. The first row shows $f 1 / f 2$ as a standard/deviant, whereas the second row shows the reverse condition ( $f 2 / f 1$ as standard/deviant). The black line lying under the dot rasters represents the stimulus duration. Common SSA index (CSI) values are shown over each condition. The mean peristimulus time histograms from both dot rasters are shown in the third row (Spk spike). b Dot raster plots obtained after an oddball paradigm for a pair of frequencies in an MGB neuron. Same format as in a. c Box plot of the CSI values for the population of neurons of the IC before, during, and after the application of GBZN. $\mathbf{d}$ Box plot of the CSI values for the population of neurons of the MGB before, during, and after the application of GBZN and GABA. In both cases, asterisks indicate significant differences (Friedman test, $P<0.01$ ). e In the absence of inhibition, neurons respond to deviants (orange) and standards (light blue) with high firing rates, and thus the deviant to standard ratio is small. f Inhibition reduces the responses to both deviants (red) and standards (dark blue) increasing the deviant to standard ratio and thus enhancing SSA. a, c, e, f: modified from Perez-Gonzalez et al. (2012). b, d: modified from Duque et al. (2014)
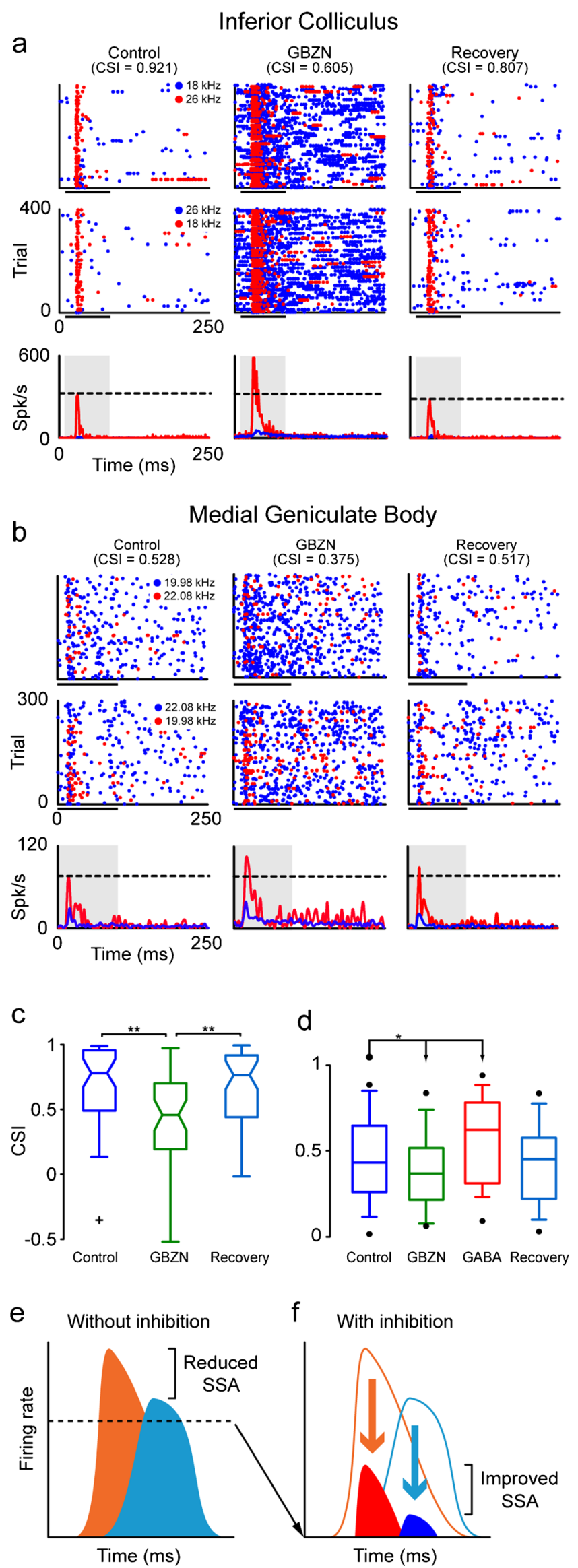
nuclei, including the substantia nigra (Minks et al. 2014), hippocampus (Ruusuvirta et al. 1995b, 1995c), basal ganglia (Mikell et al. 2014), optic tectum (Reches and Gutfreund 2008), and thalamic reticular nucleus (Yu et al. 2009). As mentioned in the previous section, some of these nuclei have anatomical connections with the non-lemniscal auditory subdivisions.

The substantia nigra is typically involved in sensorimotor coordination. However, recently, a study in humans by Mikell et al. (2014) has demonstrated that novel sounds evoke a greater firing rate compared with the activity following standard tones in substantia nigra neurons. The response following the deviant presentations displays a biphasic temporal pattern with peaks at approximately 300 and $500 \mathrm{~ms}$ (Fig. 5a). Interestingly, an inverse correlation occurs between the firing rate and the strength of the novelty response across all recorded neurons, i.e., neurons sensitive to deviant stimulus exhibit slow firing, whereas neurons with the highest firing rates are suppressed by the novel stimuli. Mikell and colleagues (2014) speculate that the substantia nigra neurons that discriminate deviant and standard tones correspond to dopaminergic neurons, since previous studies indicate dopaminergic neurons are sensitive to novelty (Bunzeck and Düzel 2006). Moreover, the former authors further suggest that the other group of substantia nigra neurons with high and tonic firing rates suppressed by the deviant tone correspond to GABAergic interneurons that are known to inhibit the local dopaminergic neurons (Tepper et al. 1995). Interestingly, the response in the substantia nigra, i.e., the first peak of the increased activity following novel sounds $(250-350 \mathrm{~ms}$ after stimulus onset), occurs concurrently with the onset of the hippocampally-dependent potential P300, a scalp-recorded potential linked to novelty detection. Notably, MMN-like responses to pitch (Ruusuvirta et al. 1995b, 1995c; 1996), duration (Rosburg et al. 2007; Ruusuvirta et al. 2013), and frequency deviants (Ruusuvirta et al. 2010) have been recorded across the hippocampus in animal studies. The hippocampus is associated with involuntary attention switches toward auditory changes of high magnitude. Ruusuvirta et al. (2013) have found that MMN responses to duration deviants are elicited across the three hippocampal areas, i.e., CA1, dentate gyrus, and subiculum in anesthetized rats. In a previous report from the same group (Ruusuvirta et al. 2010), higher amplitude local field potentials in response to frequency deviants have been recorded in the CA1 of awake animals. The MMN response to frequency and duration deviants occurs within a similar time window, at 3680 and 51.5-89 ms post-stimulus, respectively.

Recently, other non-auditory nuclei have been implicated in acoustic deviance detection. The subthalamic nucleus is integrated into the basal ganglia system, and traditionally, it is considered to play a role in cortical motor control regulation
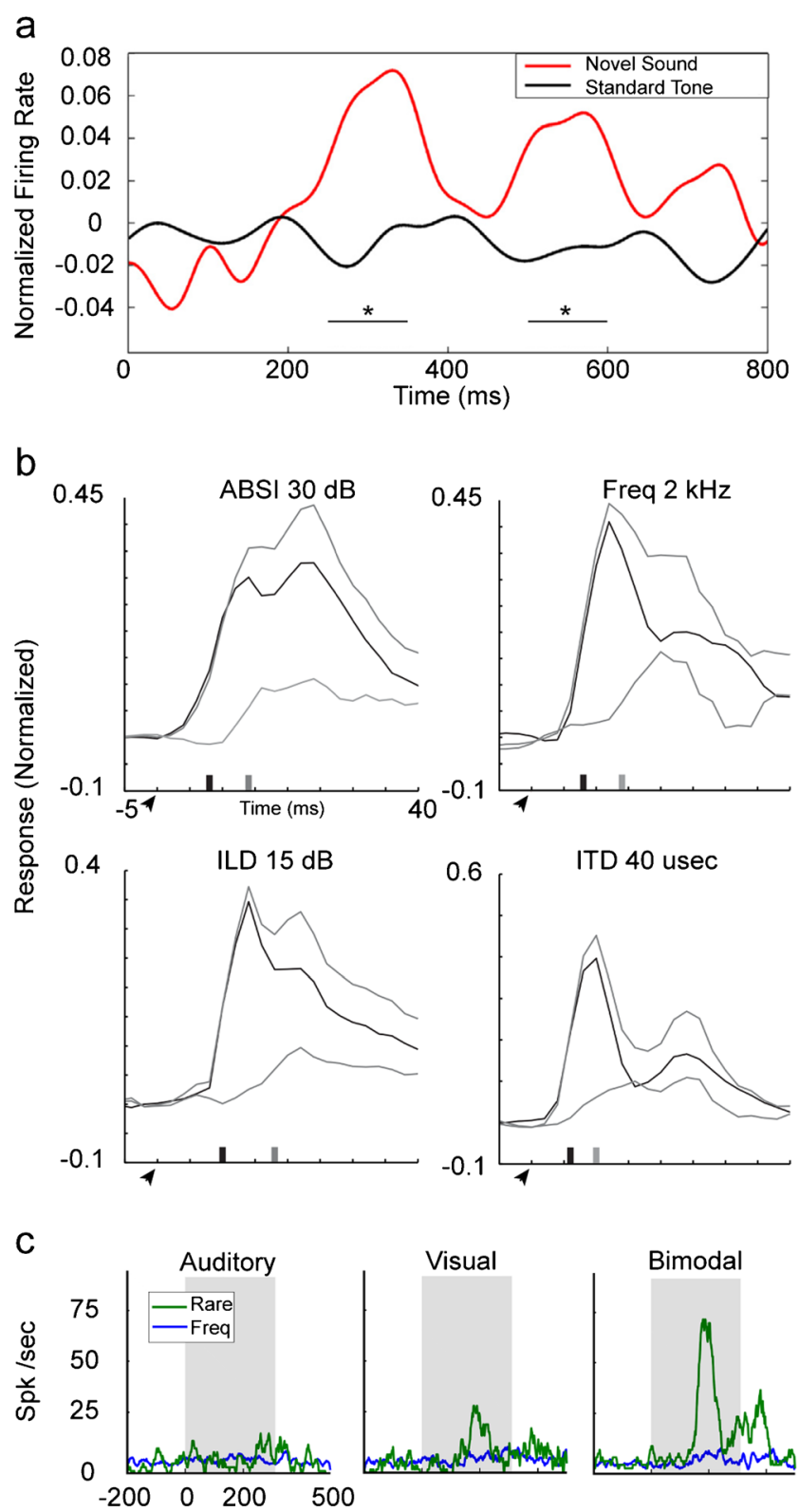

Fig. 5 Response to acoustic deviants in non-auditory subcortical nuclei. a Normalized firing response of neurons of the substantia nigra. Novel sound evoked a greater response (red line) compared with standard tones (blue line) over the 250-350 ms interval and over 500-600 ms (black lines regions of $* P<0.05$; modified from Mikell et al. 2014). b Optic tectum neuronal SSA responses to average binaural sound intensity (ABSI, $30 \mathrm{~dB}$ gap), frequency (Freq, $2 \mathrm{kHz}$ gap), interaural level difference (ILD, $15 \mathrm{~dB}$ gap), and interaural time difference (ITD, $40 \mu \mathrm{s}$ gap). Top gray line is the response to a rarely presented stimulus, black line the response to a frequently presented stimulus, bottom gray line the difference between the two, arrowheads stimulus onset, black ticks latency of the population response to the frequent stimulus, gray ticks latency of the difference signal (taken from Reches and Gutfreund 2008). c Entopallium neuronal responses to deviant occurrences (green lines) together with the corresponding responses to frequent occurrences (blue lines) of auditory, visual, and bimodal stimulus (modified from Reches et al. 2010)

(Rektor et al. 2001). Minks et al. (2014) have demonstrated that deviant pure tones elicit MMN-like responses in the 
subthalamic nuclei by using intracranial electroencephalograph recordings in humans. The responses are evident in the far-field potentials (intracerebral electrodes referenced to the extracranial electrode) and near-field potentials (intracerebral contacts referenced to one another within the subthalamic nuclei) with a similar average time-to-peak, i.e., 202 and $214 \mathrm{~ms}$, respectively.

SSA responses have been also found in the optic tectum, which is the avian homolog of the superior colliculus of mammals. The optic tectum is involved in orienting gaze toward salient stimuli and receives auditory inputs primarily from the cortices of the IC (Gutfreund 2012). In an elegant study performed by Reches and Gutfreund (2008), SSA responses to more than one acoustic feature, i.e., sound frequencies, amplitudes, and interaural and interlevel time difference, were found in the single- and multi-unit activity of the optic tectum neurons (Fig. 5b). All acoustic features elicited a similar pattern of adaptation developed several milliseconds after the onset of the response. Interestingly, neurons of the IC exhibited SSA only to sound frequency but showed a higher neuronal hyperacuity. These results led the authors to suggest that neurons in higherlevel centers of the ascending gaze control system, such as the optic tectum where the IC neurons project to, encompass SSA to multiple acoustic features and not only to one single acoustic dimension as occurs in the IC of the barn own.

The studies highlighted above clearly demonstrate that deviance detection is a widely distributed neuronal network that goes beyond the auditory pathway (Ranganath and Rainer 2003). At the same time, these studies lead to questions regarding the possibility of whether these neuronal structures play an active role in the genesis of deviance detection or simply reflect adaptive neuronal processes taking place at their projecting sources. To gain information in order to permit a direct comparison with the SSA studies, an interesting project would be to record the responses of a single neuron to various acoustic stimuli in the hippocampus, subthalamic nuclei, or superior colliculus under the same paradigms as those used in the auditory SSA studies (Ulanovsky et al. 2003; Malmierca et al. 2009; Yaron et al. 2012).

\section{Multisensory responses and deviance detection}

Neurons showing SSA also participate in multisensory processing since information integrated across various sensory modalities can greatly enhance our ability to detect, discriminate, or respond to relevant sensory events (for reviews, see Stein and Meredith 1993; Gleiss and Kayser 2012). As described previously, the non-lemniscal subdivisions of the IC and MGB in which the strongest SSA responses are found receive afferent projections not only from auditory nuclei, but also from visual and somatosensory nuclei (Wu et al. 2014). Indeed, several studies indicate that other subcortical nuclei involved in deviance detection also engage multimodal sensitivities. Neurons with multimodal sensitivity exhibit suprathreshold responses to stimuli from more than one sensory modality, and often the response of these neurons is stronger to combined stimuli than to the most effective single-modality stimulus (Meredith et al. 2012). Examples of auditory neurons whose sensitivity differs significantly when they are stimulated by bimodal (e.g., audiovisual) stimuli are summarized below. Yu et al. (2009) have found SSA responses in the thalamic reticular nucleus, a multimodal area mainly conformed by GABAergic neurons and have shown that MGB acoustic responses are modulated in a cross-modal manner by a preceding light stimulus. This modulation of the auditory responses is abolished by the inactivation of the thalamic reticular nucleus. Moreover, eye position has been demonstrated to modulate auditory responses as early as in the shell area of the IC of primates (Groh et al. 2001; for reviews, see Gruters and Groh 2012; Wu et al. 2014).

Likewise, other subcortical non-auditory structures that are particularly sensitive to deviant sound also exhibit multimodal sensitivities. Neurons in the substantia nigra are responsive to visual, auditory, and somatosensory stimulation (Nagy et al. 2005; Chudler et al. 1995) exhibiting multisensory response enhancements (Nagy et al. 2006). In the barn owl, optic tectum neurons show multisensory enhancement (Zahar et al. 2009) and SSA for visual stimuli, in addition to SSA for sound frequency deviants (Reches and Gutfreund 2008). Moreover, Reches et al. (2010) have performed a pioneering study demonstrating that a bimodal stimulus enhances the SSA responses of entopallium neurons, a forebrain structure of the barn owl (Fig. 5c). This enhancement occurs only when the auditory and visual stimuli are congruent in space and time (Reches et al. 2010). Whether the same multimodal enhancement of the auditory SSA responses occurs at early subcortical processing stages remains to be determined in future studies.

The superior colliculus is also of special interest for the exploration of SSA, because (1) the optic tectum (which is its avian homolog) encompasses SSA for multiple acoustic parameters and for visual stimulus (Reches and Gutfreund 2008) and (2) the basic principles of multisensory integration have been revealed in single-cell studies in the superior colliculus (Stein and Wallace 1996; Stein and Stanford 2008; Meredith et al. 2012). Interestingly, neurons of the superior colliculus of the anesthetized cat with little or no spontaneous activity and weak sensory responses have the ability to exhibit large multisensory response enhancements in comparison with the poor response enhancements exhibited by superior colliculus neurons with modest spontaneous activity and robust sensory responses (Perrault et al. 2003). The response features of the ongoing multisensory enhancement of the superior colliculus resemble the poor response of the IC neurons showing strong SSA (Duque et al. 2012) and those of substantia nigra neurons sensitive to deviant stimulation 
(Mikell et al. 2014). Finally, the tegmental nucleus is another multisensory structure (Koyama et al. 1994; Reese et al. 1995) in which acoustic SSA is likely to occur (Schofield et al. 2011), since its neurons attenuate or even abolish their response to repetitive auditory stimulation (Koyama et al. 1994). Furthermore, tegmental nucleus neurons project to the IC and receive projections from the AC (Schofield 2010).

All the above-mentioned studies support the notion that the subcortical nuclei engaged in auditory deviance detection constitute a neuronal microcircuitry based on the convergence of inputs from various sensory modalities that might act as early integration centers to enhance deviance detection. This wealth of data sets forth a promising field in which to explore and determine whether subcortical neurons allow better deviance coding under multisensory compared with unimodal conditions.

\section{Final remarks}

We have reviewed evidence of MMN-like and SSA responses occurring in the shell area of the IC and MGB and in nonauditory nuclei and suggest that they conform to a distributed subcortical network for deviance detection. Likewise, the topographic distribution of SSA in the shell areas of the IC and MGB suggests that the microcircuitry and neurochemistry of the non-lemniscal areas exert a critical role in the generation and modulation of SSA in these nuclei. Further studies combining physiological, anatomical, and molecular approaches will broaden our understanding of the microcircuits of SSA in the auditory and non-auditory nuclei. Moreover, these studies will contribute to the determination of the similar or different contribution of each nucleus to the processing of deviant sounds and to the triggering of the cascade of neuronal processes that allow animals to adapt rapidly to environmental changes.

\section{References}

Abbott LF, Regehr WG (2004) Synaptic computation. Nature 431:796803

Abbott LF, Varela JA, Sen K, Nelson SB (1997) Synaptic depression and cortical gain control. Science 275:220-224

Abe T, Sugihara H, Nawa H, Shigemoto R, Mizuno N, Nakanishi S (1992) Molecular characterization of a novel metabotropic glutamate receptor mGluR5 coupled to inositol phosphate/ $\mathrm{Ca}^{2+}$ signal transduction. J Biol Chem 267:13361-13368

Adams JC, Wenthold RJ (1979) Distribution of putative amino acid transmitters, choline acetyltransferase and glutamate decarboxylase in the inferior colliculus. Neuroscience 4:1947-1951

Aguilar LA, Malmierca MS, Covenas R, Lopez-Poveda EA, Tramu G, Merchan M (2004) Immunocytochemical distribution of Met-
enkephalin-Arg6-Gly7-Leu8 (Met-8) in the auditory system of the rat. Hear Res 187:111-121

Aitkin LM, Prain SM (1974) Medial geniculate body: unit responses in the awake cat. J Neurophysiol 37:512-521

Aitkin LM, Webster WR, Veale JL, Crosby DC (1975) Inferior colliculus. I. Comparison of response properties of neurons in central, pericentral, and external nuclei of adult cat. J Neurophysiol 38: 1196-1207

Aitkin LM, Dickhaus H, Schult W, Zimmermann M (1978) External nucleus of inferior colliculus: auditory and spinal somatosensory afferents and their interactions. J Neurophysiol 41:837-847

Aitkin LM, Kenyon CE, Philpott P (1981) The representation of the auditory and somatosensory systems in the external nucleus of the cat inferior colliculus. J Comp Neurol 196:25-40

Andersen RA, Knight PL, Merzenich MM (1980) The thalamocortical and corticothalamic connections of AI, AII, and the anterior auditory field (AAF) in the cat: evidence for two largely segregated systems of connections. J Comp Neurol 194:663-701

Anderson LA, Linden JF (2011) Physiological differences between histologically defined subdivisions in the mouse auditory thalamus. Hear Res 274:48-60

Anderson LA, Malmierca MS (2013) The effect of auditory cortex deactivation on stimulus-specific adaptation in the inferior colliculus of the rat. Eur J Neurosci 37:52-62

Anderson LA, Christianson GB, Linden JF (2009) Stimulus-specific adaptation occurs in the auditory thalamus. J Neurosci 29:7359-7363

Antunes FM, Malmierca MS (2011) Effect of auditory cortex deactivation on stimulus-specific adaptation in the medial geniculate body. $\mathrm{J}$ Neurosci 31:17306-17316

Antunes FM, Nelken I, Covey E, Malmierca MS (2010) Stimulusspecific adaptation in the auditory thalamus of the anesthetized rat. PLoS One 5:e14071. doi:10.1371/journal.pone.0014071

Aoki E, Semba R, Keino H, Kato K, Kashiwamata S (1988) Glycine-like immunoreactivity in the rat auditory pathway. Brain Res 442:63-71

Astikainen P, Ruusuvirta T, Wikgren J, Penttonen M (2006) Memorybased detection of rare sound feature combinations in anesthetized rats. Neuroreport 17:1561-1564

Astikainen P, Stefanics G, Nokia M, Lipponen A, Cong F, Penttonen M, Ruusuvirta T (2011) Memory-based mismatch response to frequency changes in rats. PLoS One 6:e24208. doi:10.1371/journal.pone. 0024208

Aston-Jones G (2004) Locus coeruleus, A5 and A7 noradrenergic cell groups. In: Paxinos G (ed) The rat nervous system, 3rd edn. Elsevier/Academic Press, San Diego, pp 259-294

Ayala YA, Malmierca MS (2013) Stimulus-specific adaptation and deviance detection in the inferior colliculus. Front Neural Circuits 6:89. doi:10.3389/fncir.2012.00089

Ayala YA, Perez-Gonzalez D, Duque D, Nelken I, Malmierca MS (2013) Frequency discrimination and stimulus deviance in the inferior colliculus and cochlear nucleus. Front Neural Circuits 6:119. doi: 10.3389/fncir.2012.00119

Banks MI, Smith PH (2011) Thalamocortical relations. In: Winer JA, Schreiner C (eds) The auditory cortex. Springer, New York, pp 75-97

Bartlett EL, Smith PH (1999) Anatomic, intrinsic, and synaptic properties of dorsal and ventral division neurons in rat medial geniculate body. J Neurophysiol 81:1999-2016

Bartlett EL, Smith PH (2002) Effects of paired-pulse and repetitive stimulation on neurons in the rat medial geniculate body. Neuroscience 113:957-974

Bäuerle P, Behrens W von der, Kossl M, Gaese BH (2011) Stimulusspecific adaptation in the gerbil primary auditory thalamus is the result of a fast frequency-specific habituation and is regulated by the corticofugal system. J Neurosci 31:9708-9722 
Bendixen A, SanMiguel I, Schroger E (2012) Early electrophysiological indicators for predictive processing in audition: a review. Int $\mathrm{J}$ Psychophysiol 83:120-131

Bordi F, LeDoux JE (1994a) Response properties of single units in areas of rat auditory thalamus that project to the amygdala. I. Acoustic discharge patterns and frequency receptive fields. Exp Brain Res 98: 261-274

Bordi F, LeDoux JE (1994b) Response properties of single units in areas of rat auditory thalamus that project to the amygdala. II. Cells receiving convergent auditory and somatosensory inputs and cells antidromically activated by amygdala stimulation. Exp Brain Res 98:275-286

Bowery NG, Hill DR, Hudson AL (1983) Characteristics of GABAB receptor binding sites on rat whole brain synaptic membranes. Br J Pharmacol 78:191-206

Briley PM, Krumbholz K (2013) The specificity of stimulus-specific adaptation in human auditory cortex increases with repeated exposure to the adapting stimulus. J Neurophysiol 110:2679-2688

Bunzeck N, Düzel E (2006) Absolute coding of stimulus novelty in the human substantia nigra/VTA. Neuron 51:369-79

Buran BN, Trapp G von, Sanes DH (2014) Behaviorally gated reduction of spontaneous discharge can improve detection thresholds in auditory cortex. J Neurosci 34:4076-4081

Cacciaglia R, Escera C, Slabu L, Grimm S, Sanjuán A, Ventura-Campos $\mathrm{N}$, Ávila C (2015)Involvement of the human midbrain and thalamus in auditory deviance detection.Neuropsychologia 68C:51-58

Caicedo A, Eybalin M (1999) Glutamate receptor phenotypes in the auditory brainstem and mid-brain of the developing rat. Eur J Neurosci 11:51-74

Caicedo A, Kungel M, Pujol R, Friauf E (1998) Glutamate-induced Co ${ }^{2+}$ uptake in rat auditory brainstem neurons reveals developmental changes in $\mathrm{Ca}^{2+}$ permeability of glutamate receptors. Eur J Neurosci 10:941-954

Calford MB (1983) The parcellation of the medial geniculate body of the cat defined by the auditory response properties of single units. $J$ Neurosci 3:2350-2364

Calford MB, Aitkin LM (1983) Ascending projections to the medial geniculate body of the cat: evidence for multiple, parallel auditory pathways through thalamus. J Neurosci 3:2365-2380

Cant NB, Benson CG (2003) Parallel auditory pathways: projection patterns of the different neuronal populations in the dorsal and ventral cochlear nuclei. Brain Res Bull 60:457-474

Castillo PE, Younts TJ, Chavez AE, Hashimotodani Y (2012) Endocannabinoid signaling and synaptic function. Neuron 76:70-81

Champoux F, Tremblay C, Mercier C, Lassonde M, Lepore F, Gagné JP, Théoret $\mathrm{H}$ (2006) A role for the inferior colliculus in multisensory speech integration. Neuroreport 17:1607-1610

Chernock ML, Larue DT, Winer JA (2004) A periodic network of neurochemical modules in the inferior colliculus. Hear Res 188:12-20

Chevaleyre V, Takahashi KA, Castillo PE (2006) Endocannabinoidmediated synaptic plasticity in the CNS. Annu Rev Neurosci 29: $37-76$

Christianson GB, Chait M, Cheveigne A de, Linden JF (2014) Auditory evoked fields measured non-invasively with small-animal MEG reveal rapid repetition suppression in the guinea pig. J Neurophysiol 112:3053-3065. doi:10.1152/jn.00189.2014

Chudler EH, Sugiyama K, Dong WK (1995) Multisensory convergence and integration in the neostriatum and globus pallidus of the rat. Brain Res 674:33-45

Chung S, Li X, Nelson SB (2002) Short-term depression at thalamocortical synapses contributes to rapid adaptation of cortical sensory responses in vivo. Neuron 34:437-446

Coleman JR, Clerici WJ (1987) Sources of projections to subdivisions of the inferior colliculus in the rat. J Comp Neurol 262:215-226

Coote EJ, Rees A (2008) The distribution of nitric oxide synthase in the inferior colliculus of guinea pig. Neuroscience 154:218-225
Covey E, Carr CE (2005) The auditory midbrain in bats and birds. In: Winer JA, Schreiner CE (eds) The inferior colliculus. Springer, New York, pp 493-536

Cruikshank SJ, Killackey HP, Metherate R (2001) Parvalbumin and calbindin are differentially distributed within primary and secondary subregions of the mouse auditory forebrain. Neuroscience 105:553-569

Csepe V, Karmos G, Molnar M (1987a) Effects of signal probability on sensory evoked potentials in cats. Int J Neurosci 33:61-71

Csepe V, Karmos G, Molnar M (1987b) Evoked potential correlates of stimulus deviance during wakefulness and sleep in cat-animal model of mismatch negativity. Electroencephalogr Clin Neurophysiol 66:571-578

Dean I, Robinson BL, Harper NS, McAlpine D (2008) Rapid neural adaptation to sound level statistics. J Neurosci 28:6430-6438

Doron NN, Ledoux JE (1999) Organization of projections to the lateral amygdala from auditory and visual areas of the thalamus in the rat. $\mathrm{J}$ Comp Neurol 412:383-409

Doron NN, Ledoux JE (2000) Cells in theposterior thalamus project to both amygdala and temporal cortex: a quantitative retrograde double-labeling study in the rat. J Comp Neurol 425:257-274

Druga R, Syka J (1993) NADPH-diaphorase activity in the central auditory structures of the rat. Neuroreport 4:999-1002

Duque D, Malmierca MS (2014) Stimulus-specific adaptation in the inferior colliculus of the mouse: anesthesia and spontaneous activity effects. Brain Struct Funct. doi:10.1007/s00429-014-0862-1

Duque D, Perez-Gonzalez D, Ayala YA, Palmer AR, Malmierca MS (2012) Topographic distribution, frequency, and intensity dependence of stimulus-specific adaptation in the inferior colliculus of the rat. J Neurosci 32:17762-17774

Duque D, Malmierca MS, Caspary DM (2014) Modulation of stimulusspecific adaptation by GABAA receptor activation or blockade in the medial geniculate body of the anaesthetized rat. J Physiol (Lond) 592:729-743

Edeline JM (2012) Beyond traditional approaches to understanding the functional role of neuromodulators in sensory cortices. Front Behav Neurosci 30:6-45. doi:10.3389/fnbeh.2012.00045

Edeline JM, Weinberger NM (1991) Subcortical adaptive filtering in the auditory system: associative receptive field plasticity in the dorsal medial geniculate body. Behav Neurosci 105:154-175

Escera C, Malmierca MS (2014) The auditory novelty system: an attempt to integrate human and animal research. Psychophysiology $51: 111-123$

Eytan D, Brenner N, Marom S (2003) Selective adaptation in networks of cortical neurons. J Neurosci 23:9349-9356

Fishman YI (2013) The mechanisms and meaning of the mismatch negativity. Brain Topogr 27:500-526

Fishman YI, Steinschneider M (2010) Formation of auditory streams. In: Rees A, Palmer AR (eds) The Oxford handbook of auditory science: auditory brain. Oxford University Press, New York, pp 215-245

Fishman YI, Steinschneider M (2012) Searching for the mismatch negativity in primary auditory cortex of the awake monkey: deviance detection or stimulus specific adaptation? J Neurosci 32: $15747-15758$

Foote SL, Bloom FE, Aston-Jones G (1983) Nucleus locus ceruleus: new evidence of anatomical and physiological specificity. Physiol Rev 63:844-914

Freund TF, Hajos N (2003) Excitement reduces inhibition via endocannabinoids. Neuron 38:362-365

Friauf E, Hammerschmidt B, Kirsch J (1997) Development of adult-type inhibitory glycine receptors in the central auditory system of rats. J Comp Neurol 385:117-134

Friston K (2005) A theory of cortical responses. Philos Trans R Soc Lond B Biol Sci 360:815-36

Friston K (2009) The free-energy principle: a rough guide to the brain. Trends Cogn Sci 13:293-301 
Friston K (2012) Prediction, perception and agency. Int J Psychophysiol $83: 248-252$

Fritz J, Shamma S, Elhilali M, Klein D (2003) Rapid task-related plasticity of spectrotemporal receptive fields in primary auditory cortex. Nat Neurosci 6:1216-1223

Fritz JB, Elhilali M, David SV, Shamma SA (2007) Auditory attentionfocusing the searchlight on sound. Curr Opin Neurobiol 17:437-455

Fubara BM, Casseday JH, Covey E, Schwartz-Bloom RD (1996) Distribution of GABAA, GABAB, and glycine receptors in the central auditory system of the big brown bat, Eptesicus fuscus. J Comp Neurol 369:83-92

Gaza WC, Ribak CE (1997) Immunocytochemical localization of AMPA receptors in the rat inferior colliculus. Brain Res 774:175-183

Ghazanfar AA, Maier JX, Hoffman KL, Logothetis NK (2005) Multisensory integration of dynamic faces and voices in rhesus monkey auditory cortex. J Neurosci 25:5004-5012

Gittelman JX, Perkel DJ, Portfors CV (2013) Dopamine modulates auditory responses in the inferior colliculus in a heterogeneous manner. $\mathrm{J}$ Assoc Res Otolaryngol 14:719-729

Gleiss S, Kayser C (2012) Audio-visual detection benefits in the rat. PLoS One 7:e45677. doi:10.1371/journal.pone.0045677

Graybiel AM (1972) Some ascending connections of the pulvinar and nucleus lateralis posterior of the thalamus in the cat. Brain Res 44: 99-125

Grill-Spector K, Henson R, Martin A (2006) Repetition and the brain: neural models of stimulus-specific effects. Trends Cogn Sci 10:14-23

Groh JM, Trause AS, Underhill AM, Clark KR, Inati S (2001) Eye position influences auditory responses in primate inferior colliculus. Neuron 29:509-518

Gruters KG, Groh JM (2012) Sounds and beyond: multisensory and other non-auditory signals in the inferior colliculus. Front Neural Circuits 6:96. doi:10.3389/fncir.2012.00096

Gutfreund Y (2012) Stimulus-specific adaptation, habituation and change detection in the gaze control system. Biol Cybern 106:657-668

Hari R, Hamalainen M, Ilmoniemi R, Kaukoranta E, Reinikainen K, Salminen J, Alho K, Naatanen R, Sams M (1984) Responses of the primary auditory cortex to pitch changes in a sequence of tone pips: neuromagnetic recordings in man. Neurosci Lett 50:127-132

Harley CW (2004) Norepinephrine and dopamine as learning signals. Neural Plast 11:191-204

Harms L, Fulham WR, Todd J, Budd TW, Hunter M, Meehan C, Penttonen M, Schall U, Zavitsanou K, Hodgson DM, Michie PT (2014) Mismatch negativity (MMN) in freely-moving rats with several experimental controls. PLoS One 9:e110892. doi:10.1371/ journal.pone. 0110892

He J, Hu B (2002) Differential distribution of burst and single-spike responses in auditory thalamus. J Neurophysiol 88:2152-2156

Herbert H, Klepper A, Ostwald J (1997) Afferent and efferent connections of the ventrolateral tegmental area in the rat. Anat Embryol (Berl) 196:235-259

Herkenham M, Lynn AB, Little MD, Johnson MR, Melvin LS, Costa BR de, Rice KC (1990) Cannabinoid receptor localization in brain. Proc Natl Acad Sci U S A 87:1932-1936

Hershenhoren I, Taaseh N, Antunes FM, Nelken I (2014) Intracellular correlates of stimulus-specific adaptation. J Neurosci 34:3303-3319

Hormigo S, Horta Junior Jde A, Gomez-Nieto R, Lopez DE (2012) The selective neurotoxin DSP-4 impairs the noradrenergic projections from the locus coeruleus to the inferior colliculus in rats. Front Neural Circuits 6:41. doi:10.3389/fncir.2012.00041

$\mathrm{Hu}$ B (2003) Functional organization of lemniscal and nonlemniscal auditory thalamus. Exp Brain Res 153:543-549

Hu B, Senatorov V, Mooney D (1994) Lemniscal and non-lemniscal synaptic transmission in rat auditory thalamus. J Physiol (Lond) $479: 217-231$
Huang CL, Winer JA (2000) Auditory thalamocortical projections in the cat: laminar and areal patterns of input. J Comp Neurol 427:302e331

Hurley LM, Pollak GD (2005) Serotonin shifts first-spike latencies of inferior colliculus neurons. J Neurosci 25:7876-7886

Hurley LM, Sullivan MR (2012) From behavioral context to receptors: serotonergic modulatory pathways in the IC. Front Neural Circuits 6:58. doi:10.3389/fncir.2012.00058

Hurley LM, Thompson AM, Pollak GD (2002) Serotonin in the inferior colliculus. Hear Res 168:1-11

Itaya SK, Van Hoesen GW (1982) Retinal innervation of the inferior colliculus in rat and monkey. Brain Res 233:45-52

Ito T, Bishop DC, Oliver DL (2011) Expression of glutamate and inhibitory amino acid vesicular transporters in the rodent auditory brainstem. J Comp Neurol 519:316-340

Iwata K, Kenshalo DR Jr, Dubner R, Nahin RL (1992) Diencephalic projections from the superficial and deep laminae of the medullary dorsal horn in the rat. J Comp Neurol 321:404-420

Jaaskelainen IP, Ahveninen J, Bonmassar G, Dale AM, Ilmoniemi RJ, Levanen S, Lin FH, May P, Melcher J, Stufflebeam S, Tiitinen H, Belliveau JW (2004) Human posterior auditory cortex gates novel sounds to consciousness. Proc Natl Acad Sci U S A 101:6809-6814

Jacobsen T, Schröger E (2003) Measuring duration mismatch negativity. Clin Neurophysiol 114:1133-1143

Jain R, Shore S (2006) External inferior colliculus integrates trigeminal and acoustic information: unit responses to trigeminal nucleus and acoustic stimulation in the guinea pig. Neurosci Lett 395:71-75

Jamal L, Zhang H, Finlayson PG, Porter LA, Zhang H (2011) The level and distribution of the GABA(B)R2 receptor subunit in the rat's central auditory system. Neuroscience 181:243-256

Jamal L, Khan AN, Butt S, Patel CR, Zhang H (2012) The level and distribution of the GABA(B)R1 and GABA(B)R2 receptor subunits in the rat's inferior colliculus. Front Neural Circuits 6:92. doi:10. 3389/fncir.2012.00092

Javitt DC, Schroeder CE, Steinschneider M, Arezzo JC, Vaughan HG Jr (1992) Demonstration of mismatch negativity in the monkey. Electroencephalogr Clin Neurophysiol 83:87-90

Javitt DC, Steinschneider M, Schroeder CE, Vaughan HG Jr, Arezzo JC (1994) Detection of stimulus deviance within primate primary auditory cortex: intracortical mechanisms of mismatch negativity (MMN) generation. Brain Res 667:192-200

Ji W, Gao E, Suga N (2001) Effects of acetylcholine and atropine on plasticity of central auditory neurons caused by conditioning in bats. J Neurophysiol 86:211-225

Jones BE (2005) From waking to sleeping: neuronal and chemical substrates. Trends Pharmacol Sci 26:578-586

Jones EG (2003) Chemically defined parallel pathways in the monkey auditory system. Ann N Y Acad Sci 999:218-233

Jong AP de, Verhage M (2009) Presynaptic signal transduction pathways that modulate synaptic transmission. Curr Opin Neurobiol 19: $245-253$

Jung F, Stephan KE, Backes H, Moran R, Gramer M, Kumagai T, Graf R, Endepols H, Tittgemeyer M (2013) Mismatch responses in the awake rat: evidence from epidural recordings of auditory cortical fields. PLoS One 8:e63203. doi:10.1371/journal.pone.0063203

Kano M, Ohno-Shosaku T, Hashimotodani Y, Uchigashima M, Watanabe M (2009) Endocannabinoid-mediated control of synaptic transmission. Physiol Rev 89:309-380

Kayser C, Logothetis NK (2007) Do early sensory cortices integrate cross-modal information? Brain Struct Funct 212:121-132

Kayser C, Petkov CI, Remedios R, Logothetis NK (2012) Multisensory influences on auditory processing: perspectives from fMRI and electrophysiology. In: Murray MM, Wallace MT (eds) The neural bases of multisensory processes. CRC Press, Boca Raton, pp 99-114

Kelly JB (1973) The effects of insular and temporal lesions in cats on two types of auditory pattern discrimination. Brain Res 62:71-87 
Kelly J, Caspary D (2005) Pharmacology of the inferior colliculus. In: Winer J, Schreiner CE (eds) The inferior colliculus. Springer, New York, pp 248-281

Kelly JB, Zhang H (2002) Contribution of AMPA and NMDA receptors to excitatory responses in the inferior colliculus. Hear Res 168:35-42

King AJ, Walker KM (2012) Integrating information from different senses in the auditory cortex. Biol Cybern 106:617-25

King AJ, Jiang ZD, Moore DR (1998) Auditory brainstem projections to the ferret superior colliculus: anatomical contribution to the neural coding of sound azimuth. J Comp Neurol 390:342-365

Klepper A, Herbert H (1991) Distribution and origin of noradrenergic and serotonergic fibers in the cochlear nucleus and inferior colliculus of the rat. Brain Res 557:190-201

Komura Y, Tamura R, Uwano T, Nishijo H, Kaga K, Ono T (2001) Retrospective and prospective coding for predicted reward in the sensory thalamus. Nature 412:546-549

Koyama Y, Jodo E, Kayama Y (1994) Sensory responsiveness of "broadspike" neurons in the laterodorsal tegmental nucleus, locus coeruleus and dorsal raphe of awake rats: implications for cholinergic and monoaminergic neuron-specific responses. Neuroscience 63:1021-1031

Kraus N, McGee T, Carrell T, King C, Littman T, Nicol T (1994a) Discrimination of speech-like contrasts in the auditory thalamus and cortex. J Acoust Soc Am 96:2758-2768

Kraus N, McGee T, Littman T, Nicol T, King C (1994b) Nonprimary auditory thalamic representation of acoustic change. J Neurophysiol 72:1270-1277

Kudo M, Niimi K (1980) Ascending projections of the inferior colliculus in the cat: an autoradiographic study. J Comp Neurol 191:545-556

Lakatos P, Chen CM, O'Connell MN, Mills A, Schroeder CE (2007) Neuronal oscillations and multisensory interaction in primary auditory cortex. Neuron 53:279-292

Lavoie B, Parent A (1991) Serotoninergic innervation of the thalamus in the primate: an immunohistochemical study. J Comp Neurol 312:118. doi: $10.1002 / \mathrm{cne} .903120102$

Layton BS, Toga AW, Horenstein S, Davenport DG (1979) Temporal pattern discrimination survives simultaneous bilateral ablation of suprasylvian cortex but not sequential bilateral ablation of insulartemporal cortex in the cat. Brain Res 173:337-340

LeDoux JE, Ruggiero DA, Forest R, Stornetta R, Reis DJ (1987) Topographic organization of convergent projections to the thalamus from the inferior colliculus and spinal cord in the rat. J Comp Neurol 264:123-146

Lee CC, Sherman SM (2010) Topography and physiology of ascending streams in the auditory tectothalamic pathway. Proc Natl Acad Sci U S A 107:372-377

Lee CC, Sherman SM (2011) On the classification of pathways in the auditory midbrain, thalamus, and cortex. Hear Res 276:79-87

Lee CC, Winer JA (2011) Convergence of thalamic and cortical pathways in cat auditory cortex. Hear Res 274:85-94

Lennartz RC, Weinberger NM (1992) Frequency selectivity is related to temporal processing in parallel thalamocortical auditory pathways. Brain Res 583:81-92

Li Y, Evans MS, Faingold CL (1998) In vitro electrophysiology of neurons in subnuclei of rat inferior colliculus. Hear Res 121:1-10

Li Y, Evans MS, Faingold CL (1999) Synaptic response patterns of neurons in the cortex of rat inferior colliculus. Hear Res 137:15-28

Loftus WC, Malmierca MS, Bishop DC, Oliver DL (2008) The cytoarchitecture of the inferior colliculus revisited: a common organization of the lateral cortex in rat and cat. Neuroscience 154:196-205

Loftus WC, Bishop DC, Oliver DL (2010) Differential patterns of inputs create functional zones in central nucleus of inferior colliculus. $\mathrm{J}$ Neurosci 30:13396-13408
Lohmann C, Friauf E (1996) Distribution of the calcium-binding proteins parvalbumin and calretinin in the auditory brainstem of adult and developing rats. J Comp Neurol 367:90-109

Lu Y, Jen PH (2001) GABAergic and glycinergic neural inhibition in excitatory frequency tuning of bat inferior collicular neurons. Exp Brain Res 141:331-339

Lumani A, Zhang H (2010) Responses of neurons in the rat's dorsal cortex of the inferior colliculus to monaural tone bursts. Brain Res 1351:115-129

Ma CL, Kelly JB, Wu SH (2002) AMPA and NMDA receptors mediate synaptic excitation in the rat's inferior colliculus. Hear Res 168:25-34

Maess B, Jacobsen T, Schroger E, Friederici AD (2007) Localizing preattentive auditory memory-based comparison: magnetic mismatch negativity to pitch change. Neuroimage 37:561-571

Malmierca MS, Hackett TA (2010) Structural organization of the ascending auditory pathway. In: Rees A, Palmer AR (eds) The Oxford handbook of auditory science: auditory brain. Oxford University Press, New York, pp 9-41

Malmierca MS, Seip KL, Osen KK (1995) Morphological classification and identification of neurons in the inferior colliculus: a multivariate analysis. Anat Embryol (Berl) 191:343-350

Malmierca MS, Izquierdo MA, Cristaudo S, Hernandez O, PerezGonzalez D, Covey E, Oliver DL (2008) A discontinuous tonotopic organization in the inferior colliculus of the rat. J Neurosci 28:4767-4776

Malmierca MS, Cristaudo S, Perez-Gonzalez D, Covey E (2009) Stimulus-specific adaptation in the inferior colliculus of the anesthetized rat. J Neurosci 29:5483-5493

Malmierca MS, Blackstad TW, Osen KK (2011) Computer-assisted 3-D reconstructions of Golgi-impregnated neurons in the cortical regions of the inferior colliculus of rat. Hear Res 274:13-26

Manunta Y, Edeline JM (2004) Noradrenergic induction of selective plasticity in the frequency tuning of auditory cortex neurons. $\mathrm{J}$ Neurophysiol 92:1445-1463

Mascetti GG, Strozzi L (1988) Visual cells in the inferior colliculus of the cat. Brain Res 442:387-390

May PJ, Tiitinen H (2010) Mismatch negativity (MMN), the devianceelicited auditory deflection, explained. Psychophysiology 47: 66-122

McCormick DA, Pape HC (1990) Noradrenergic and serotonergic modulation of a hyperpolarization-activated cation current in thalamic relay neurones. J Physiol (Lond) 431:319-342

Merchan M, Aguilar LA, Lopez-Poveda EA, Malmierca MS (2005) The inferior colliculus of the rat: quantitative immunocytochemical study of GABA and glycine. Neuroscience 136:907-925

Meredith MA, Allman BL, Keniston LP, Clemo HR (2012) Are bimodal neurons the same throughout the brain? In: Murray MM, Wallace MT (eds) The neural bases of multisensory processes. CRC Press, Boca Raton, http://www.ncbi.nlm.nih.gov/books/NBK92874/

Metherate R, Weinberger NM (1989) Acetylcholine produces stimulusspecific receptive field alterations in cat auditory cortex. Brain Res 480:372-377

Metherate R, Intskirveli I, Kawai HD (2012) Nicotinic filtering of sensory processing in auditory cortex. Front Behav Neurosci 6:44. doi:10. 3389/fnbeh.2012.00044

Mikell CB, Sheehy JP, Youngerman BE, McGovern RA, Wojtasiewicz TJ, Chan AK, Pullman SL, Yu Q, Goodman RR, Schevon CA, McKhann GM 2nd (2014) Features and timing of the response of single neurons to novelty in the substantia nigra. Brain Res 1542: 79-84

Mill R, Coath M, Wennekers T, Denham SL (2011a) Abstract stimulusspecific adaptation models. Neural Comput 23:435-476

Mill R, Coath M, Wennekers T, Denham SL (2011b) A neurocomputational model of stimulus-specific adaptation to oddball and Markov sequences. PLoS Comput Biol 7:e1002117 
Miller LM, Escabi MA, Read HL, Schreiner CE (2001) Functional convergence of response properties in the auditory thalamocortical system. Neuron 32:151-160

Minks E, Jurák P, Chládek J, Chrastina J, Halámek J, Shaw DJ, Bareš M (2014) Mismatch negativity-like potential (MMN-like) in the subthalamic nuclei in Parkinson's disease patients. J Neural Transm 121:1507-1522. doi:10.1007/s00702-014-1221-3

Molinari M, Dell'Anna ME, Rausell E, Leggio MG, Hashikawa T, Jones EG (1995) Auditory thalamocortical pathways defined in monkeys by calcium-binding protein immunoreactivity. J Comp Neurol 362: 171-194

Monaghan DT, Cotman CW (1985) Distribution of N-methyl-Daspartate-sensitive $\mathrm{L}-[3 \mathrm{H}]$ glutamate-binding sites in rat brain. J Neurosci 5:2909-2919

Monckton JE, McCormick DA (2002) Neuromodulatory role of seroto$\operatorname{nin}$ in the ferret thalamus. J Neurophysiol 87:2124-2136

Moore RY, Bloom FE (1979) Central catecholamine neuron systems: anatomy and physiology of the norepinephrine and epinephrine systems. Annu Rev Neurosci 2:113-168

Moran RJ, Campo P, Symmonds M, Stephan KE, Dolan RJ, Friston KJ (2013) Free energy, precision and learning: the role of cholinergic neuromodulation. J Neurosci 33:8227-8236

Morris RG (2013) NMDA receptors and memory encoding. Neuropharmacology 74:32-40

Movshon JA, Lennie P (1979) Pattern-selective adaptation in visual cortical neurons. Nature 278:850-852

Näätänen R, Gaillard AW, Mantysalo S (1978) Early selective-attention effect on evoked potential reinterpreted. Acta Psychol (Amst) 42: 313-329

Näätänen R, Tervaniemi M, Sussman E, Paavilainen P, Winkler I (2001) "Primitive intelligence" in the auditory cortex. Trends Neurosci 24: 283-288

Nagy A, Paróczy Z, Norita M, Benedek G (2005) Multisensory responses and receptive field properties of neurons in the substantia nigra and in the caudate nucleus. Eur J Neurosci 22:419-424

Nagy A, Eördegh G, Paróczy Z, Márkus Z, Benedek G (2006) Multisensory integration in the basal ganglia. Eur J Neurosci 24: 917-924

Nakamura T, Michie PT, Fulham WR, Todd J, Budd TW, Schall U, Hunter M, Hodgson DM (2011) Epidural auditory event-related potentials in the rat to frequency and duration deviants: evidence of mismatch negativity? Front Psychol 2:367. doi:10.3389/fpsyg. 2011.00367

Nelken I (2014) Stimulus-specific adaptation and deviance detection in the auditory system: experiments and models. Biol Cybern 108: 655-663. doi:10.1007/s00422-014-0585-7

Nelken I, Ulanovsky N (2007) Mismatch negativity and stimulus-specific adaptation in animal models. J Psychophysiol 21:214-223

Nir Y, Vyazovskiy VV, Cirelli C, Banks MI, Tononi G (2013) Auditory responses and stimulus-specific adaptation in rat auditory cortex are preserved across NREM and REM sleep. Cereb Cortex. doi:10. 1093/cercor/bht328

Olazabal UE, Moore JK (1989) Nigrotectal projection to the inferior colliculus: horseradish peroxidase transport and tyrosine hydroxylase immunohistochemical studies in rats, cats, and bats. J Comp Neurol 282:98-118

Oliver DL (2005) Neuronal organization in the inferior colliculus. In: Schreiner CE, Winer JA (eds) The inferior colliculus. New York, Springer, pp 69-131

Oliver DL, Huerta MF (1992) Inferior and superior colliculi. In: Webster DB, Popper AN, Fay RR (eds) Springer handbook of auditory research, vol 1 . The mammalian auditory pathway: neuroanatomy. Springer, New York, pp 168-221

Opitz B, Schröger E, Cramon DY von (2005) Sensory and cognitive mechanismsfor preattentive change detection in auditory cortex. Eur J Neurosci 21:531-535
Ouda L, Syka J (2012) Immunocytochemical profiles of inferior colliculus neurons in the rat and their changes with aging. Front Neural Circuits 6:68. doi:10.3389/fncir.2012.00068

Paloff AM, Hinova-Palova DV (1998) Topographical distribution of NADPH-diaphorase positive neurons in the cat's inferior colliculus. J Hirnforsch 39:231-243

Paloff AM, Usunoff KG (2000) Tyrosine hydroxylase-like immunoreactive synaptic boutons in the inferior colliculus of the cat. Ann Anat $182: 423-426$

Pape HC, McCormick DA (1989) Noradrenaline and serotonin selectively modulate thalamic burst firing by enhancing a hyperpolarizationactivated cation current. Nature 340:715-718

Parks TN (2000) The AMPA receptors of auditory neurons. Hear Res 147:77-91

Penzo MA, Pena JL (2009) Endocannabinoid-mediated long-term depression in the avian midbrain expressed presynaptically and postsynaptically. J Neurosci 29:4131-4139

Perez-Gonzalez D, Malmierca MS, Covey E (2005) Novelty detector neurons in the mammalian auditory midbrain. Eur J Neurosci 22: 2879-2885

Perez-Gonzalez D, Hernandez O, Covey E, Malmierca MS (2012) GABA(A)-mediated inhibition modulates stimulus-specific adaptation in the inferior colliculus. PLoS One 7:e34297. doi:10.1371/ journal.pone.0034297

Perrault TJ Jr, Vaughan JW, Stein BE, Wallace MT (2003) Neuronspecific response characteristics predict the magnitude of multisensory integration. J Neurophysiol 90:4022-4026

Peruzzi D, Bartlett E, Smith PH, Oliver DL (1997) A monosynaptic GABAergic input from the inferior colliculus to the medial geniculate body in rat. J Neurosci 17:3766-3777

Petralia RS, Wenthold RJ (1992) Light and electron immunocytochemical localization of AMPA-selective glutamate receptors in the rat brain. J Comp Neurol 318:329-354

Petralia RS, Yokotani N, Wenthold RJ (1994) Light and electron microscope distribution of the NMDA receptor subunit NMDAR1 in the rat nervous system using a selective anti-peptide antibody. J Neurosci 14:667-696

Pincze Z, Lakatos P, Rajkai C, Ulbert I, Karmos G (2001) Separation of mismatch negativity and the N1 wave in the auditory cortex of the cat: a topographic study. Clin Neurophysiol 112:778-784

Pincze Z, Lakatos P, Rajkai C, Ulbert I, Karmos G (2002) Effect of deviant probability and interstimulus/interdeviant interval on the auditory N1 and mismatch negativity in the cat auditory cortex. Brain Res Cogn Brain Res 13:249-253

Ranganath C, Rainer G (2003) Neural mechanisms for detecting and remembering novel events. Nat Rev Neurosci 4:193-202

Reches A, Gutfreund Y (2008) Stimulus-specific adaptation in the gaze control system of the barn owl. J Neurosci 28:1523-1533

Reches A, Netser S, Gutfreund Y (2010) Interactions between stimulusspecific adaptation and visual auditory integration in the forebrain of the barn owl. J Neurosci 30:6991-6998

Reese NB, Garcia-Rill E, Skinner RD (1995) Auditory input to the pedunculopontine nucleus. II. Unit responses. Brain Res Bull 37: 265-273

Regehr WG (2012) Short-term presynaptic plasticity. Cold Spring Harb Perspect Biol 4:a005702. doi:10.1101/cshperspect.a005702

Regehr WG, Carey MR, Best AR (2009) Activity-dependent regulation of synapses by retrograde messengers. Neuron 63:154-170

Rektor I, Bares M, Kubová D (2001) Movement-related potentials in the basal ganglia: a SEEG readiness potential study. Clin Neurophysiol 112:2146-2153

Richardson BD, Ling LL, Uteshev VV, Caspary DM (2011) Extrasynaptic GABA(A) receptors and tonic inhibition in rat auditory thalamus. PLoS One 6:e16508. doi:10.1371/journal.pone. 0016508 
Romand R, Ehret G (1990) Development of tonotopy in the inferior colliculus. I. Electrophysiological mapping in house mice. Brain Res Dev Brain Res 54:221-234

Rosburg T, Trautner P, Ludowig E, Schaller C, Kurthen M, Elger CE, Boutros NN (2007) Hippocampal event-related potentials to tone duration deviance in a passive oddball paradigm in humans. Neuroimage 37:274-281

Rothman JS, Cathala L, Steuber V, Silver RA (2009) Synaptic depression enables neuronal gain control. Nature 457:1015-1018

Rouiller EM, Colomb E, Capt M, De Ribaupierre F (1985) Projections of the reticular complex of the thalamus onto physiologically characterized regions of the medial geniculate body. Neurosci Lett 53:227-232

Ruusuvirta T, Korhonen T, Penttonen M, Arikoski J (1995a) Hippocampal evoked potentials to pitch deviances in an auditory oddball situation in the rabbit: no human mismatch-like dependence on standard stimuli. Neurosci Lett 185:123-126

Ruusuvirta T, Korhonen T, Penttonen M, Arikoski J, Kivirikko K (1995b) Behavioral and hippocampal evoked responses in an auditory oddball situation when an unconditioned stimulus is paired with deviant tones in the cat: experiment II. Int J Psychophysiol 20:41-47

Ruusuvirta T, Korhonen T, Penttonen M, Arikoski J, Kivirikko K (1995c) Hippocampal event-related potentials to pitch deviances in an auditory oddball situation in the cat: experiment I. Int J Psychophysiol 20:33-39

Ruusuvirta T, Korhonen T, Arikoski J, Kivirikko K (1996) ERPs to pitch changes: a result of reduced responses to standard tones in rabbits. Neuroreport 7:413-416

Ruusuvirta T, Penttonen M, Korhonen T (1998) Auditory cortical eventrelated potentials to pitch deviances in rats. Neurosci Lett 248:45-48

Ruusuvirta T, Astikainen P, Wikgren J, Nokia M (2010) Hippocampus responds to auditory change in rabbits. Neuroscience 170:232-237

Ruusuvirta T, Lipponen A, Pellinen E, Penttonen M, Astikainen P (2013) Auditory cortical and hippocampal-system mismatch responses to duration deviants in urethane-anesthetized rats. PLoS One 8: e54624. doi:10.1371/journal.pone.0054624

Saint Marie RL, Ostapoff EM, Morest DK, Wenthold RJ (1989) Glycineimmunoreactive projection of the cat lateral superior olive: possible role in midbrain ear dominance. J Comp Neurol 279:382-396

Sanchez-Gonzalez MA, Garcia-Cabezas MA, Rico B, Cavada C (2005) The primate thalamus is a key target for brain dopamine. J Neurosci 25:6076-6083

Sanes DH, Geary WA, Wooten GF, Rubel EW (1987) Quantitative distribution of the glycine receptor in the auditory brain stem of the gerbil. J Neurosci 7:3793-3802

Sato K, Kiyama H, Park HT, Tohyama M (1993) AMPA, KA and NMDA receptors are expressed in the rat DRG neurones. Neuroreport 4: $1263-1265$

Schofield BR (2010) Projections from auditory cortex to midbrain cholinergic neurons that project to the inferior colliculus. Neuroscience 166:231-240

Schofield BR, Motts SD, Mellott JG (2011) Cholinergic cells of the pontomesencephalic tegmentum: connections with auditory structures from cochlear nucleus to cortex. Hear Res 279:85-95

Schröger E, Wolff C (1996) Mismatch response of the human brain to changes in sound localization. Neuroreport 7:3005-3008

Shigemoto R, Nomura S, Ohishi H, Sugihara H, Nakanishi S, Mizuno N (1993) Immunohistochemical localization of a metabotropic glutamate receptor, mGluR5, in the rat brain. Neurosci Lett 163:53-57

Shinonaga Y, Takada M, OgawaMeguro R, Ikai Y, Mizuno N (1992) Direct projections from the globus pallidus to the midbrain and pons in the cat. Neurosci Lett 135:179-183

Shinonaga Y, Takada M, Mizuno N (1994) Direct projections from the non-laminated divisions of the medial geniculate nucleus to the temporal polar cortex and amygdala in the cat. J Comp Neurol 340:405-426
Shiramatsu TI, Kanzaki R, Takahashi H (2013) Cortical mapping of mismatch negativity with deviance detection property in rat. PLoS One 8:e82663. doi:10.1371/journal.pone.0082663

Shore SE (2008) Auditory/somatosensory interactions. In: Adelman G, Smith BH (eds) The new encyclopedia of neurosciences. Elsevier Science, Amsterdam

Siegel SJ, Connolly P, Liang Y, Lenox RH, Gur RE, Bilker WB, Kanes SJ, Turetsky BI (2003) Effects of strain, novelty, and NMDA blockade on auditory-evoked potentials in mice. Neuropsychopharmacology 28:675-682

Slabu L, Escera C, Grimm S, Costa-Faidella J (2010) Early change detection in humans as revealed by auditory brainstem and middlelatency evoked potentials. Eur J Neurosci 32:859-865

Slabu L, Grimm S, Escera C (2012) Novelty detection in the human auditory brainstem. J Neurosc 32:1447-452

Smith PH, Bartlett EL, Kowalkowski A (2007) Cortical and collicular inputs to cells in the rat paralaminar thalamic nuclei adjacent to the medial geniculate body. J Neurophysiol 98:681-695

Stebbings KA, Lesicko AM, Llano DA (2014) The auditory corticocollicular system: molecular and circuit-level considerations. Hear Res 314:51-59

Stein BE, Meredith MA (1993) The merging of the senses. MIT Press, Cambridge

Stein BE, Stanford TR (2008) Multisensory integration: current issues from the perspective of the single neuron. Nat Rev Neurosci 9: 255-266

Stein BE, Wallace MT (1996) Comparisons of cross-modality integration in midbrain and cortex. Prog Brain Res 112:289-299

Swanson LW, Hartman BK (1975) The central adrenergic system. An immunofluorescence study of the location of cell bodies and their efferent connections in the rat utilizing dopamine-beta-hydroxylase as a marker. J Comp Neurol 163:467-505

Taaseh N, Yaron A, Nelken I (2011) Stimulus-specific adaptation and deviance detection in the rat auditory cortex. PLoS One 6:e23369. doi:10.1371/journal.pone. 0023369

Tardif E, Chiry O, Probst A, Magistretti PJ, Clarke S (2003) Patterns of calcium-binding proteins in human inferior colliculus: identification of subdivisions and evidence for putative parallel systems.Neuroscience 116:1111-1121

Tebecis AK (1970) Effects of monoamines and amino acids on medial geniculate neurones of the cat. Neuropharmacology 9:381-390

Tebecis AK (1972) Cholinergic and non-cholinergic transmission in the medial geniculate nucleus of the cat. J Physiol 226:153-172

Tepper JM, Martin LP, Anderson DR (1995) GABAA receptor mediated inhibition of rat substantia nigra dopaminergic neurons by pars reticulata projection neurons. J Neurosci 15:3092-3103

Tong L, Altschuler RA, Holt AG (2005) Tyrosine hydroxylase in rat auditory midbrain: distribution and changes following deafness. Hear Res 206:28-41

Tongjaroenbuangam W, Jongkamonwiwat N, Phansuwan-Pujito P, Casalotti SO, Forge A, Dodson H, Govitrapong P (2006) Relationship of opioid receptors with GABAergic neurons in the rat inferior colliculus. Eur J Neurosci 24:1987-1994

Trattner B, Berner S, Grothe B, Kunz L (2013) Depolarization-induced suppression of a glycinergic synapse in the superior olivary complex by endocannabinoids. J Neurochem 127:78-90

Ulanovsky N, Las L, Nelken I (2003) Processing of low-probability sounds by cortical neurons. Nat Neurosci 6:391-398

Ulanovsky N, Las L, Farkas D, Nelken I (2004) Multiple time scales of adaptation in auditory cortex neurons. J Neurosci 24:10440-10453

Umbricht D, Vyssotki D, Latanov A, Nitsch R, Lipp HP (2005) Deviance-related electrophysiological activity in mice: is there mismatch negativity in mice? Clin Neurophysiol 116:353-363

Varela C (2014) Thalamic neuromodulation and its implications for executive networks. Front Neural Circuits 8:69. doi:10.3389/fncir. 2014.00069 
Varela C, Sherman SM (2007) Differences in response to muscarinic activation between first and higher order thalamic relays. J Neurophysiol 98:3538-3547

Varela C, Sherman SM (2009) Differences in response to serotonergic activation between first and higher order thalamic nuclei. Cereb Cortex 19:1776-1786

Vater M, Braun K (1994) Parvalbumin, calbindin D-28 k, and calretinin immunoreactivity in the ascending auditory pathway of horseshoe bats. J Comp Neurol 341:534-558

Venecia RK de, Smelser CB, Lossman SD, McMullen NT (1995) Complementary expression of parvalbumin and calbindin D-28 k delineates subdivisions of the rabbit medial geniculate body. J Comp Neurol 359:595-612

Vertes RP, Linley SB, Hoover WB (2010) Pattern of distribution of serotonergic fibers to the thalamus of the rat. Brain Struct Funct 215:1-28

Wenstrup JJ (2005) The tectothalamic system. In: Winer JA, Schreiner CE (eds) The inferior colliculus. Springer, New York, pp 69-131

Westerman LA, Smith RL (1985) Rapid adaptation depends on the characteristic frequency of auditory nerve fibers. Hear Res 17:197-198

Wilson RI, Nicoll RA (2002) Endocannabinoid signaling in the brain. Science 296:678-682

Wilson RI, Kunos G, Nicoll RA (2001) Presynaptic specificity of endocannabinoid signaling in the hippocampus. Neuron 31:453-462

Winer JA (1992) The functional architecture of the medial geniculate body and the primary auditory cortex. In: Webster DB, Popper AN, Fay RR (eds) Springer handbook of auditory research, vol 1. The mammalian auditory pathway: neuroanatomy. Springer, New York, pp 222-409

Winer JA, Larue DT (1996) Evolution of GABAergic circuitry in the mammalian medial geniculate body. Proc Natl Acad Sci U S A 93: 3083-3087

Winer JA, Saint Marie RL, Larue DT, Oliver DL (1996) GABAergic feedforward projections from the inferior colliculus to the medial geniculate body. Proc Natl Acad Sci U S A 93:8005-8010
Winkler I, Denham SL, Nelken I (2009) Modeling the auditory scene: predictive regularity representations and perceptual objects. Trends Cogn Sci 13:532-540

Wu C, Stefanescu RA, Martel DT, Shore SE (2014) Listening to another sense: somatosensory integration in the auditory system. Cell Tissue Res. doi:10.1007/s00441-014-2074-7

Wynne B, Robertson D (1997) Somatostatin and substance P-like immunoreactivity in the auditory brainstem of the adult rat. J Chem Neuroanat 12:259-266

Yamauchi K, Yamadori T (1982) Retinal projection to the inferior colliculus in the rat. Acta Anat (Basel) 114:355-360

Yaron A, Hershenhoren I, Nelken I (2012) Sensitivity to complex statistical regularities in rat auditory cortex. Neuron 76:603-615

Yasui Y, Nakano K, Kayahara T, Mizuno N (1991) Nondopaminergic projections from the substantia nigra pars lateralis to the inferior colliculus in the rat. Brain Res 559:139-144

Yu XJ, Xu XX, He S, He J (2009) Change detection by thalamic reticular neurons. Nat Neurosci 12:1165-1170

Zahar Y, Reches A, Gutfreund Y (2009) Multisensory enhancement in the optic tectum of the barn owl: spike count and spike timing. J Neurophysiol 101:2380-2394

Zettel ML, Carr CE, O'Neill WE (1991) Calbindin-like immunoreactivity in the central auditory system of the mustached bat, Pteronotus parnelli. J Comp Neurol 313:1-16

Zhao L, Liu Y, Shen L, Feng L, Hong B (2011) Stimulus-specific adaptation and its dynamics in the inferior colliculus of rat. Neuroscience 181:163-174

Zhao Y, Tzounopoulos T (2011) Physiological activation of cholinergic inputs controls associative synaptic plasticity via modulation of endocannabinoid signaling. J Neurosci 31:3158-3168

Zhao Y, Rubio ME, Tzounopoulos T (2009) Distinct functional and anatomical architecture of the endocannabinoid system in the auditory brainstem. J Neurophysiol 101:2434-2446 